\title{
Mars Rotorcraft: Possibilities, Limitations, and Implications For Human/Robotic Exploration
}

\author{
Larry A. Young \\ Edwin Aiken \\ Army/NASA Rotorcraft Division \\ NASA Ames Research Center, MS 243-12 \\ Moffett Field, CA 94035-1000 \\ 650-604-4022 \\ larry.a.young@nasa.gov
}

\author{
Pascal Lee \\ Mars Institute and SETI Institute \\ NASA Ames Research Center, MS 245-3 \\ Moffett Field, CA 94035-1000
}

\author{
Geoffrey Briggs \\ Center for Mars Exploration \\ NASA Ames Research Center, MS 239-20 \\ Moffett Field, CA 94035-1000
}

Abstract $^{1,2}$-Several research investigations have examined the challenges and opportunities in the use of small robotic rotorcraft for the exploration of Mars. To date, only vehicles smaller than $150 \mathrm{~kg}$ have been studied. This paper proposes to examine the question of maximum Mars rotorcraft size, range, and payload/cargo capacity. Implications for the issue of whether or not (from an extreme design standpoint) a manned Mars rotorcraft is viable are also discussed.

\section{TABLE OF CONTENTS}

1. INTRODUCTION ... 1

2. LIMITS TO ROTOR GROWTH ......................................... 2

3. AERIAL EXPLORER: MAXIMUM RANGE ........................ 4

4. Autonomous UTILITY VehiCle: MAXIMUM

PAYLOAD

5. IMPLICATIONS FOR A MANNED VEHICLE .010 .10 .10 .6

6. THE LARGE VERSUS THE MANY

7. OTHER ROBOTIC MISSIONS .......................................... 9

8. SMART Rotorcraft FiELd ASSISTANTS..................... 10

9. THE FUTURE............................................................. 10

10. CONCLUDING REMARKS .......................................... 11

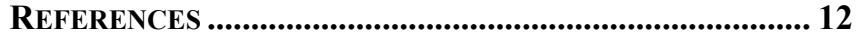

APPENDIX A - ANALYSIS/DISCUSSION ON SMALL TO MID-

SIZE MARS ROTORCRAFT 13

APPENDIX B - WEIGHT/SIZING FOR MID TO LARGE MARS

ROTORCRAFT 18

\section{INTRODUCTION}

Every new scientific or engineering endeavor must at some point answer two fundamental questions: 1) is the concept feasible, and 2) what are the physical limits of application? As regards the Mars rotorcraft concept, a modest body of work has attempted to address the issue of the feasibility of small robotic rotorcraft for Mars exploration. The area of application holds great promise. However, to date, the second question has not been considered with any rigor. The question of how large a rotor/rotorcraft can theoretically be developed is still an ongoing subject of discussion and research even for terrestrial aircraft, but an envelope of possibilities for Mars can be defined given what is known today about the martian atmosphere and surface environment.

Most Mars rotorcraft work to date has focused on small, fully robotic, platforms to perform relatively near-term Mars science investigations $[1,15,16,24,25]$. A spectrum of capability can be envisioned if larger rotorcraft, perhaps assembled with human assistance, could be employed. Table 1 provides a limited assessment of those capabilities and the advantages and disadvantages of larger versus smaller Mars rotorcraft.

\footnotetext{
${ }^{1}$ U.S. Government work not protected by U.S. copyright.

2 IEEEAC paper \#1274, Version 3, Updated December 16, 2004.
} 
Table 1. Merits and Limitations of Large and Small Mars Rotorcraft

\begin{tabular}{|c|c|}
\hline & mall Rotorcraft \\
\hline & Capabilities \\
\hline & $\begin{array}{l}\text { - Perform efficient short- and mid-range "low and slow" } \\
\text { aerial surveys }\end{array}$ \\
\hline & - Take off and land at remote unprepared sites \\
\hline & $\begin{array}{l}\text { - Drop small probes and sensors and/or acquire small } \\
\text { samples of soil and rocks }\end{array}$ \\
\hline & $\begin{array}{l}\text { - Act as advance scouts for human explorers or large } \\
\text { robotic rovers }\end{array}$ \\
\hline & - Act as, or transport and install, telecom and data relays \\
\hline & - Perform high-risk and/or "expendable" tasks \\
\hline & Advantages \\
\hline & $\begin{array}{l}\text { - One or many Mars rotorcraft working together in } \\
\text { concert }\end{array}$ \\
\hline & $\begin{array}{l}\text { - Almost de facto robotic symbiosis of small rotorcraft } \\
\text { working with other robotic/automated systems }\end{array}$ \\
\hline & Disadvantages \\
\hline & $\begin{array}{l}\text { - Range limited for small platforms to an operational } \\
\text { radius of less than } 50 \mathrm{~km}\end{array}$ \\
\hline & $\begin{array}{l}\text { - Relatively high energy expenditure for a robotic asset, } \\
\text { but not too high as compared to other equipment required } \\
\text { for human exploration of Mars }\end{array}$ \\
\hline & Large Rotorcraft \\
\hline & Capabilities \\
\hline & $\begin{array}{l}\text { - Can carry more sophisticated instrument packages than } \\
\text { smaller platforms }\end{array}$ \\
\hline & ge than smaller platforms \\
\hline & - Medium size high-value payloads point to point \\
\hline & $\begin{array}{l}\text { - Possibly act as a short to mid-range "manned" transport } \\
\text { platform }\end{array}$ \\
\hline & $\begin{array}{rr}\text { Advantages } \\
\end{array}$ \\
\hline & $\begin{array}{l}\text { - In general, at most, one or two larger rotorcraft work } \\
\text { together to perform tasks }\end{array}$ \\
\hline & $\begin{array}{l}\text { - Larger rotorcraft would be used for campaigns leading } \\
\text { up to and including human exploration }\end{array}$ \\
\hline & $\begin{array}{rr}\text { Disadvantages } \\
\end{array}$ \\
\hline & $\begin{array}{l}\text { - Range for larger vehicles increases to an operational } \\
\text { range of a couple hundred kilometers }\end{array}$ \\
\hline & $\begin{array}{l}\text { Larger rotorcraft consume large quantities of energy; } \\
\text { however, compared to energy requirements for ISRU for } \\
\text { return-to-Earth propellant, or human habitat and base camp } \\
\text { power needs, then energy levels required are not too } \\
\text { excessive }\end{array}$ \\
\hline
\end{tabular}

Additional mission architecture issues to be dealt with for Mars rotorcraft are: 1. the relative tradeoff between teleoperation and complete vehicle autonomy for Mars rotorcraft, 2. mission tradeoffs between a few large or many small Mars rotorcraft, and 3. the relatively near-term mission potential of small robotic Mars rotorcraft for meeting Mars exploration science objectives as well as building technology infrastructure for future human exploration.

Clearly as the human element is incorporated into mission architecture concepts there are considerable differences (both positive and negative) in the technology challenges for small and large Mars rotorcraft. One example is the potential use of different propulsion technologies for the aerial explorers. Small early robotic missions would likely require electric propulsion (battery or fuel cell) while human/robotic missions might use in-situ-derived propellants and higher power-density engines. Another example is the potential use of teleoperation and scaleable autonomy for the aerial explorer, versus implementing full autonomy (no human intervention) or restricting and simplifying missions/flight objectives.

\section{Limits TO Rotor GROWTH}

There are two general categories of terrestrial examples of maximum rotor size attained to date: human-powered helicopters (HPH), such as the Cal Poly "Da Vinci III" and the Tokyo Institute of Science and Technology's "Yuri I", and the heavy-lift helicopter (HLH), such as the Sikorsky S64 Flying Crane. Currently, work is underway to examine very large terrestrial rotorcraft with payloads on the order of 20 tons, or 120 passengers for commercial variants. One of the key challenges of all Mars rotorcraft, but especially so for very large vehicles, is the development of robust ultralightweight rotor hardware that can survive high blade tip speeds (hover tip Mach numbers ranging from 0.5 to 0.7 ).

What are the potential limiting factors that constrain the maximum size of rotors - terrestrial or for Mars? There are essential three constraints that effect the growth of rotor size: 1. strength of materials (under centrifugal loading, see Fig.1) considerations, 2. rotating hardware weight trends (rotor, hub, and control systems), and 3. transmission and drive-train torque and weight limitations.

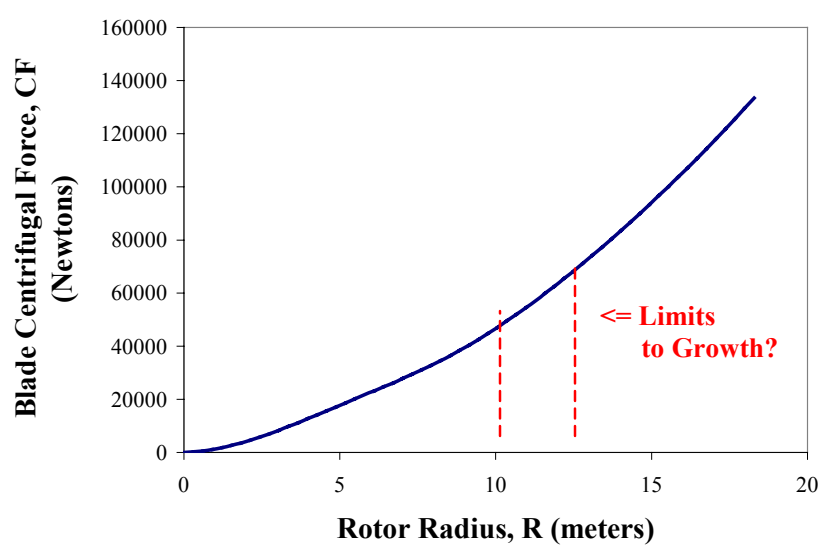

Fig. 1 - Blade Centrifugal Force Trend (N) for Mars Rotors 
Figure 2 is a first-order estimate of Mars rotor weight trends as a function of rotor size. Two curves are shown. The general methodology, a.k.a. weight equations, are from [17, 18, 22]. Appropriate calibration factors have been applied to "calibrate," or scale, the weight trends against prototype "baseline" Mars rotor blades documented in [24-26]. This calibration implies that Mars rotor blades only weigh roughly about ten to fourteen percent of their equivalently sized terrestrial rotorcraft blades. The ultra-lightweight nature of Mars rotorcraft blades is an essential design requirement. Mars rotorcraft must employ ultra-lightweight construction techniques in order to be feasible, irrespective of the size of the vehicle, given the mandatory large blade surface area and rotor radii necessary to provide adequate lift to operate in Mars' thin atmosphere. The first curve is the Mars rotor (single) blade mass trend calibrated to the baseline first-generation (2.44 meter diameter) prototype blades. The second curve represents the assumed weight trend of an optimized blade design, assuming a $25 \%$ knockdown factor against the baseline blade design. The Mars rotor weight estimates are based on a notional set of configurations having four-bladed rotors with a tip Mach number of 0.65 , a blade geometric solidity of 0.2 , and a first flap frequency of 1.2 per rev (which has only a secondary influence on the mass estimate). More details as to the weight sizing estimates can be found in Appendices A-B.

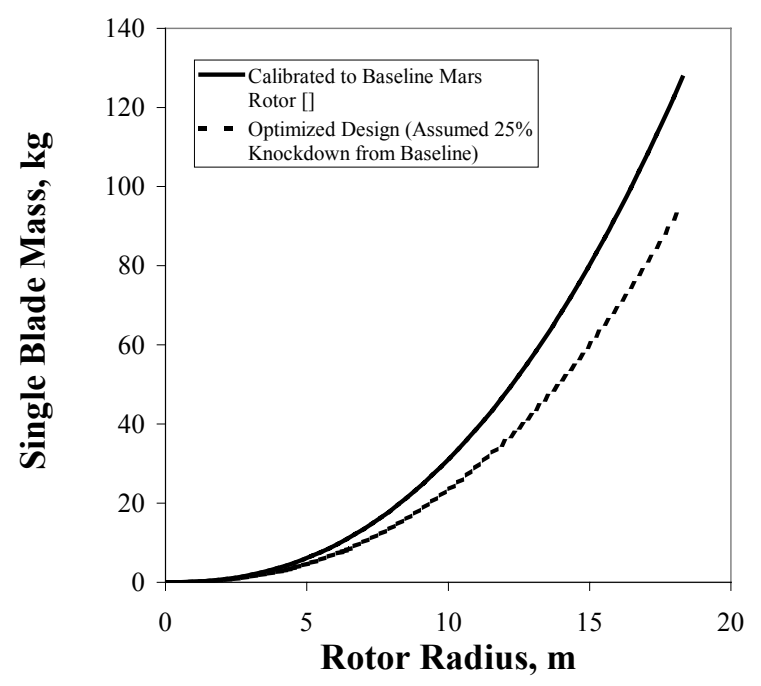

Fig. 2 - Projected Mars Rotor (per Blade) Weight Trend

As noted earlier, blade mass is a critical contributor to the overall gross weight of a Mars rotorcraft - far more so than for a terrestrial rotorcraft. Percent weight contribution of blade to the vehicle total mass will typically range between $10-30 \%$ for small to mid-size rotors. But, as the rotors become larger $(\sim R>12$ meters), this percent weight contribution increases significantly.

Control system weight growth with rotor size for Mars rotors may dictate the pursuit of alternate control approaches than that of conventional collective/cyclic pitchlink and swashplate control systems, whose weight trend is shown in Fig. 3. Onboard, embedded servo-flaps and actuators might instead present a low-weight solution to rotor trim control.

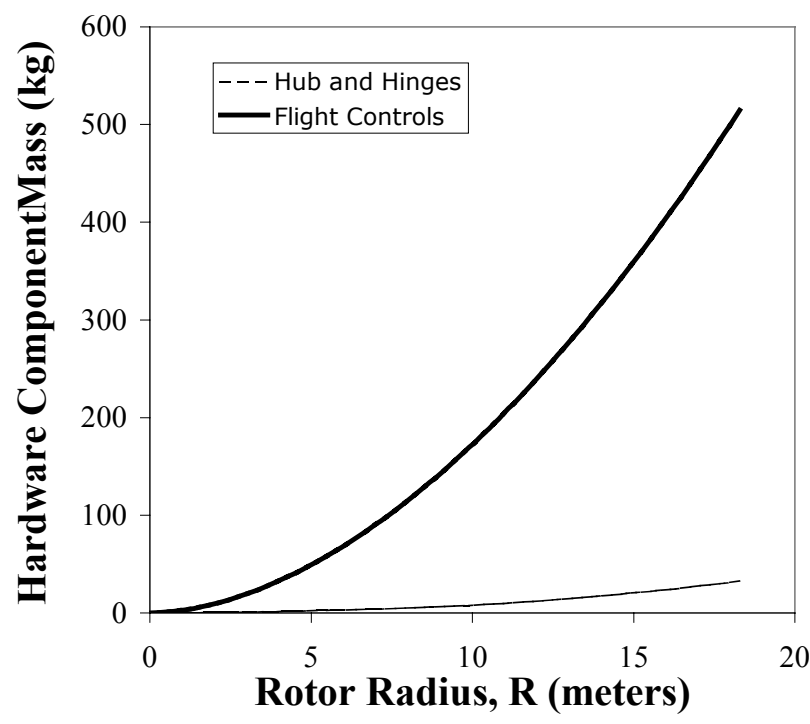

Fig. 3 - Hub and Flight Controls Weight Trends (kg) for Mars Rotorcraft

As noted earlier, drive train (including transmissions) and engine weight also has a key influence on maximum allowable rotor size. Figure 4 shows representative weight trends for the drive train and engines for Mars rotorcraft.

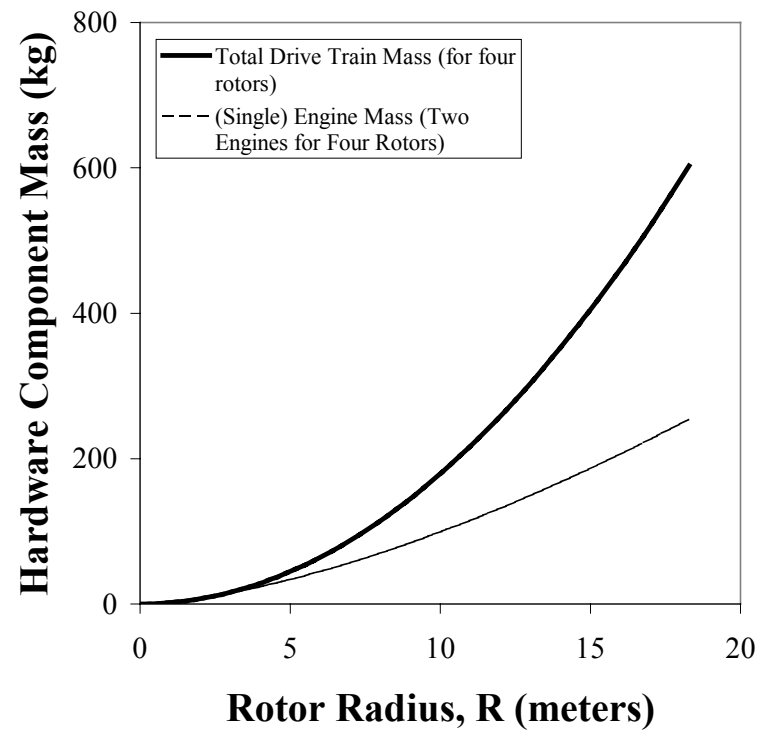

Fig. 4 - Drive Train and Engine (Hydrazine Akkerman) Weight Trends for Mars Rotorcraft 
Overall it appears that Mars rotors can grow to somewhere around the range of about 10-12 meters before blade centrifugal (CF) loads starts rising rapidly (Fig. 1). The blade CF growth appears to scale approximately linearly up to about this limit. As blade chordwise cross-sectional area should proportionally scale with blade radius (with constant solidity) the blade stresses should be roughly constant up to 10-12 meter rotor radius. Therefore, a structurally robust blade design should be scalable within this rotor size range. Beyond 10-12 meters, though, the blade stress to strength ratio will tend to grow in magnitude as rotor size increases. This implies that higher disk loading vehicles $\sim 6 \mathrm{~N} / \mathrm{m}^{2}$, versus $4 \mathrm{~N} / \mathrm{m}^{2}$, are preferred from a weight and structural perspective for large Mars rotorcraft. Smaller vehicles could be designed as lower disk loading machines (3$\left.5 \mathrm{~N} / \mathrm{m}^{2}\right)$.

Although the above noted considerations are key to limiting the potential growth of rotor and rotorcraft size, there are other several secondary constraints that also have important implications for sizing of "large" rotorcraft - especially for Mars rotorcraft. One of the concerns regarding the use of Mars rotorcraft is the extent of "brownout" occurrence with the rotor downwash dispersing/suspending fine dust particles from the martian surface into the local Mars atmosphere (Fig. 5). Rotor disk loading greater than $3 \mathrm{~N} / \mathrm{m}^{2}$ deserves increased scrutiny as to the occurrence and severity of brownout during low-level and hovering flight for Mars rotorcraft. The rotor wake horizontal velocity estimates are based on methodology from [9-11]. Martian saltation threshold velocities are taken from [12-14]. The occurrence of brownout becomes especially critical if vision-based systems are used for Mars rotorcraft landing at remote sites.

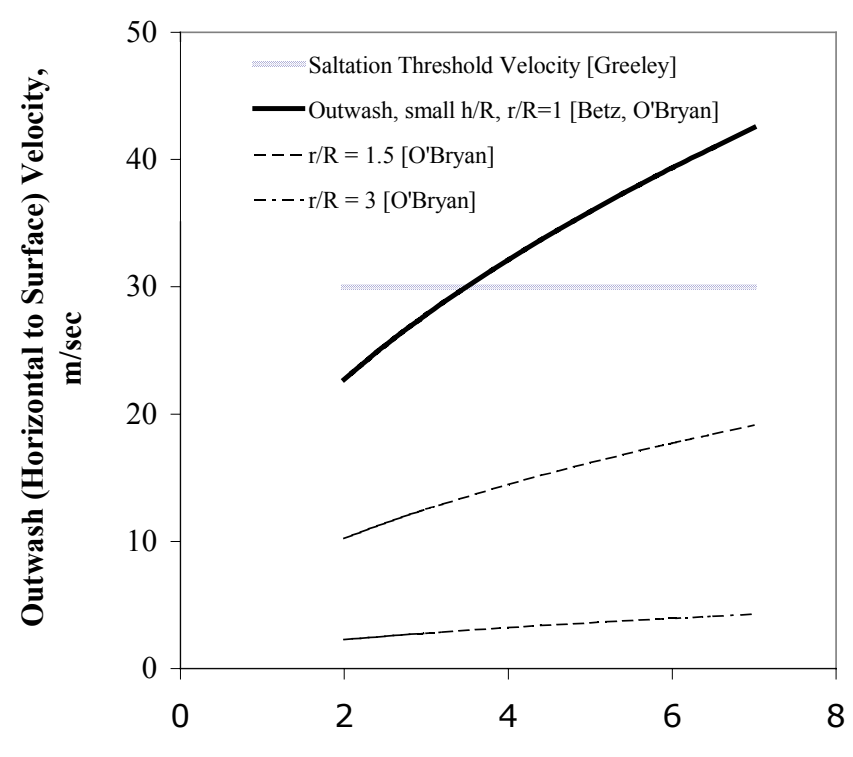

Individual (Single) Rotor Disk Loading, T/A, N/m^2

Fig. 5 - Constraints on "Brownout" During Mars Rotorcraft Operation

\section{Aerial Explorer: Maximum Range}

In order to maximize vehicle range for exploration, it will be necessary to consider alternative, more efficient, rotorcraft configurations from those of helicopter-type vehicles. Two viable contenders for a mid- to long-range vertical lift aerial explorer are the tiltrotor (Fig. 6) and tail-sitter concepts (for terrestrial versions, refer to [31]). Being able to effect rotor conversion/transition from rotary- to fixed-wing flight, though, will be especially challenging for Mars tiltrotors and tail-sitters. A limited amount of work has been performed to date examining Mars tiltrotor vehicles (10 and $150 \mathrm{~kg}$ point designs). It is clear though, to fully utilize such vehicles, that the simplicity of electric propulsion will have to be sacrificed for power-plants with higher power/energy densities (such as hydrazine Ackerman engines). Further, even tiltrotor/tailsitter vehicles with relatively small "gross weight" masses will likely require astronaut assembly, because of the large wing surfaces entailed by these vehicles. Nonetheless, longer range rotorcraft aerial explorers are in principle feasible and should continue to be examined in more detail for combined robotic and human exploration missions.
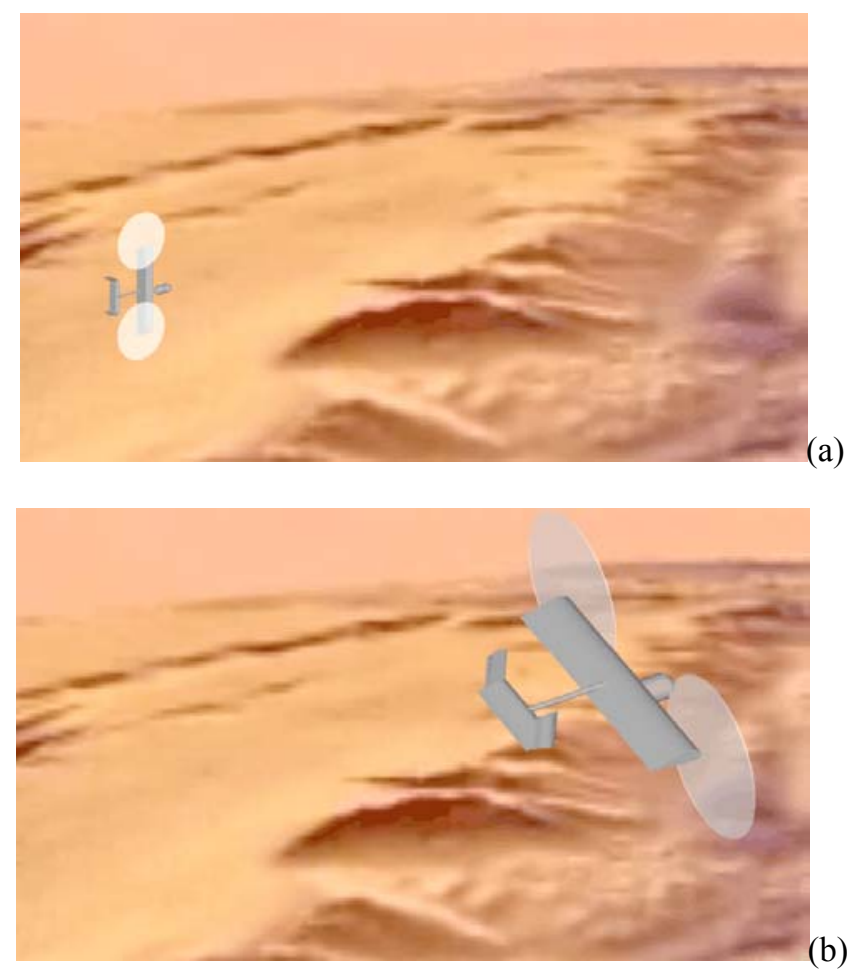

Fig. 6 -- A Mars Tiltrotor: (a) helicopter-mode in vertical climb over Valles Marineris and (b) in airplane-mode

Table 2 summarizes some of the influences of aerial explorer range on mission capability. Range is an important consideration for the Mars rotorcraft (as it is for all aerial explorers), but a considerable body of work of scientific merit can also be accomplished with vehicles with fairly short-range capacity. 
Table 2. Influence of Range on Mission Capability

\section{$<25 \mathrm{~km}$}

- Distribute small sensors as well as acquire small samples of soil/rocks at remote sites

- Ability to fly in and out of next-generation EDLS entry error ellipses; i.e. allows for lander touchdown in a "safe zone," but then provides aerial mobility to get to otherwise inaccessible terrain

\section{$>50 \mathrm{~km}$}

- Ability to fly beyond the boundaries of current state-ofthe-art EDLS entry error ellipses for lander touchdown

- Mission scenarios at this operational range are very similar to $<25 \mathrm{~km}$ vehicles, with the exception that more refined/advanced search and find strategies can be employed as well as multiple remote site landings per flight

\section{$>200 \mathbf{~ k m}$}

- Adequate range and overall efficiency to perform search and find missions of terrain features of interest that are not a priori known to mission planners

- At this operational range and beyond, vehicle becomes a viable platform for advance scouting for human expeditionary treks

- To achieve this range, more diverse and efficient vehicle configurations (such as Mars tiltrotors) are required

\section{$>500 \mathbf{~ k m}$}

- With this range capability (and overall performance), vehicles can perform wide-ranging, comprehensive (i.e. exhaustive search) mapping of regional terrain

- At this operational range, vehicle becomes a viable platform for regional-scale climatology and atmospheric chemistry measurements

\section{Autonomous Utility Vehicle: MaXimum PAYLOAD}

Table 3 summarizes some of the potential mission applications for autonomous utility/cargo rotary-wing vehicles. This mission capability is directly proportional to the vehicle mass. To date, most of the Mars rotorcraft work has been focused on the under $50 \mathrm{~kg}$ class of vehicles. This paper is the first to consider larger rotary-wing platforms for Mars exploration. The greater lift capacity of these larger vehicles opens up new mission capabilities that the smaller vehicles are unable to attain. The penultimate theoretical capability of these larger vehicles $(>2500 \mathrm{~kg})$ is their possible use as manned transport platforms. Even so, developing a vehicle capable of carrying a single spacesuited passenger, with reasonable support system capability, is likely pushing the limits of rotor growth capability for Mars rotorcraft.
Table 3. Gross Weight and Mission Utility

\section{$<50 \mathbf{~ k g}$}

- In this "gross weight" category of vehicles, only coaxial and/or quad-rotor designs (because of their compactness or ease of storage/deployment) make practical sense $[15,16]$, as these vehicles will likely be used for early purely robotic campaigns

- Because of mass and energy density limitations vehicles in this gross weight category have to work in robotic symbiosis with other robotic/automated assets

- Rotary-wing assets of this gross weight category - but not much larger -- can either be part of, or adjunct to, "hybrid" vehicles used for planetary exploration (reference, for example, the "aerial surveyor" concept discussed below)

\section{$>150 \mathrm{~kg}$}

- More sophisticated onboard remote-sensing equipment can start being employed on this gross weight class of vehicles; this includes use of lidar and radar type systems

- Less reliance for this class of vehicle on lander/rover assets for in-situ analysis support (which can now be carried on the vehicle); more reliance on such systems and/or base camp for power and maintenance.

- Post-mission (after the astronauts leave) autonomous vehicle science campaign support

\section{$>1000 \mathrm{Kg}$}

- In this gross weight category, the vehicle evolves from a sensor-platform to a utility/carrier platform; groundpenetrating radars, drills, micro-rovers, etc, can be transported to remote sites by the utility vehicles

\section{$>2500 \mathrm{~kg}$}

- Limited-quantity acquisition of resources versus science sample (such as volatiles/ice from polar region)

- Search and rescue (for stranded or disabled astronauts on treks away from base camp, on foot or by rover)

- Could also serve double-duty as either a teleoperated and autonomous platform or a manned vehicle

As noted above in Tables 2 and 3, an increasing number of mission scenarios suggest themselves as vehicle size increases. This is not unlike the advancement in capability seen/anticipated for robotic rovers with Sojourner, MER (Mars Exploration Rovers, "Spirit" and "Opportunity"), and the future MSL (Mobile Science Laboratory). A large aerial vehicle might, for example, be used for flying alongside steep geologic formations and canyons. It could also be used for forward camp emplacement of resources for ground expeditions or remote science stations. 


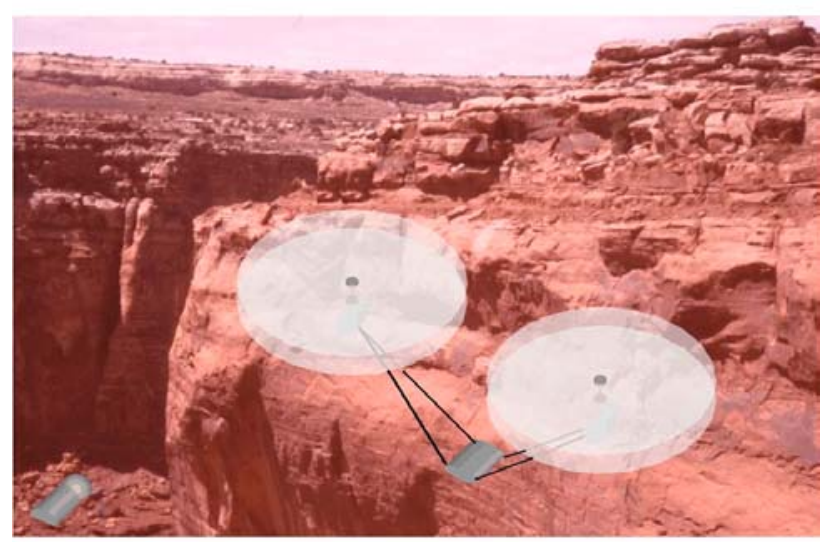

Fig. 7 - Delivering Equipment to Forward Bases

A considerable amount of research has been conducted with regards to using a "twin lift" approach (Fig. 7) for the hauling of large external payloads. ("Twin lift" refers to the use of two free-flying rotorcraft using slings to support a common external payload.) Such an approach might be a satisfactory solution to the autonomous cargo rotorcraft problem. Further, two such coaxial rotorcraft could be hardmounted by a truss structure to form a semi-modular coaxial-tandem manned variant. This will be discussed next.

\section{IMPLiCATIONS FOR A MANNED VEHICLE}

After a journey of months and millions of miles, it is almost inconceivable to envision astronauts' explorations to be limited to within walking distance of their landers and base camp. Using human-rated rovers is fraught with attendant risks and limitations. Alternate concepts for astronaut transport/mobility such as fixed-wing airplanes, ballistic hoppers, and balloons suffer from their own technical challenges and risks [19-20]. Some of the feasibility issues underlying the hypothetical development of a manned Mars rotorcraft are discussed next.

The notional tandem-coaxial helicopter shown in Fig. 8a-b would have rotor diameters ranging from 22.9 to 30.5 meters, assuming a disk loading from 6 to $4 \mathrm{~N} / \mathrm{m}^{2}$. This assumes a combined passenger and payload mass of $275 \mathrm{~kg}$. A non-pressurized, rudimentary control cabin is assumed for the vehicle; essentially only a simple windscreen would be provided. All environmental support would be provided for by the pilot astronaut's spacesuit. Weight trend estimates from Fig. 2 reveal that an unacceptable blade weight fraction results for the 30.5 meter diameter $4 \mathrm{~N} / \mathrm{m}^{2}$ disk-load vehicle ( $\sim 50 \%$ for an anticipated "optimized" rotor design); the 22.9 meter diameter, $6 \mathrm{~N} / \mathrm{m}^{2}$ disk-load vehicle has a more reasonable - though still high by even Mars rotor standards -- blade weight fraction estimate $(\sim 30 \%)$. Going from the somewhat more lightly loaded rotor to the greater disk-load, though, will result in an increased likelihood of raising dust during take-off and landing, as per Fig. 5 results. Dust mitigation steps would need to be taken.

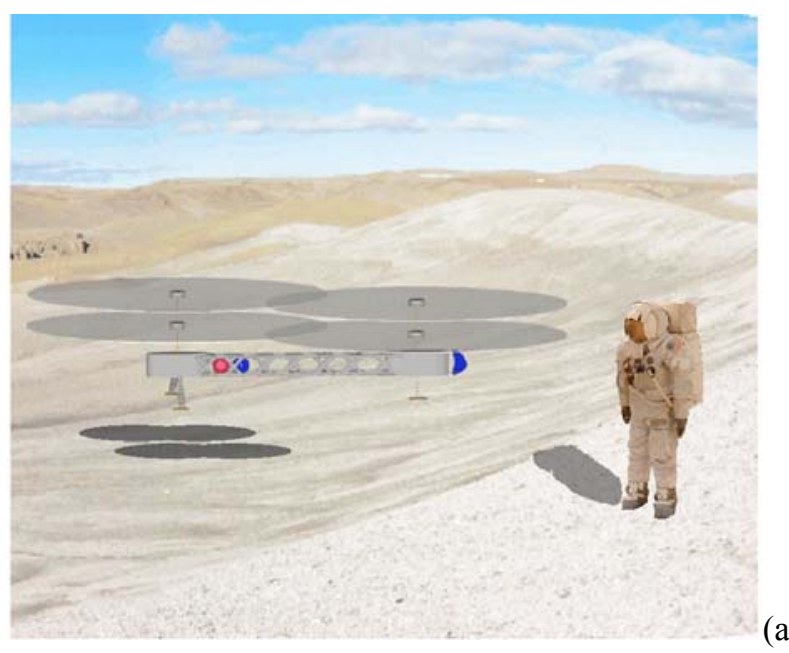

(a)

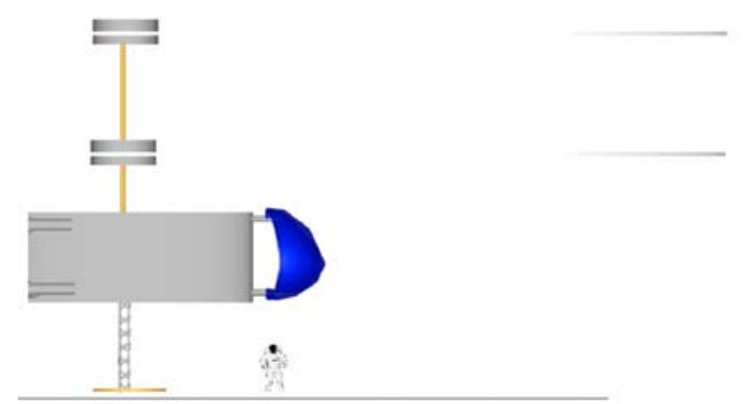

(b)

Fig. 8 - Notional Tandem-Coaxial Helicopter Configuration

Overlapping inter-meshing rotors are preferred from an overall vehicle dimensions perspective as (to minimize longitudinal vehicle span) well as from safety considerations (both sets of rotors would keep spinning synchronously if there was a engine(s) failure). There are many examples of conventional terrestrial manned helicopters of the tandem and coaxial helicopters configuration. There are also small radio-controlled terrestrial versions of quad-rotor designs, as well as plans for large manned variants (the Bell QuadTiltrotor as being the key example). Additionally, small (twenty kilograms or less) quad-rotor vehicles have already been proposed for Mars rotorcraft [15, 21]. A tandemcoaxial helicopter, terrestrial or Mars-variant, is a unique configuration, and as such there is considerable opportunity for aeromechanics research for this vehicle-type.

It is not simply because it is physically large that makes the idea of a manned Mars rotorcraft daunting. Many other vehicles are equally as large or larger - refer to Fig. 9. Though it is of ultra-lightweight construction, the vehicle will need to be largely assembled by space-suited 
astronauts; tools and infrastructure (such as a "hanger") will be minimal or nonexistent. Even if it is concluded that manned Mars rotorcraft are impractical (though theoretically possible), pushing the boundaries of the possible with regards to vehicle size increases overall mission capability for Mars rotorcraft, as suggested previously in Table 3.

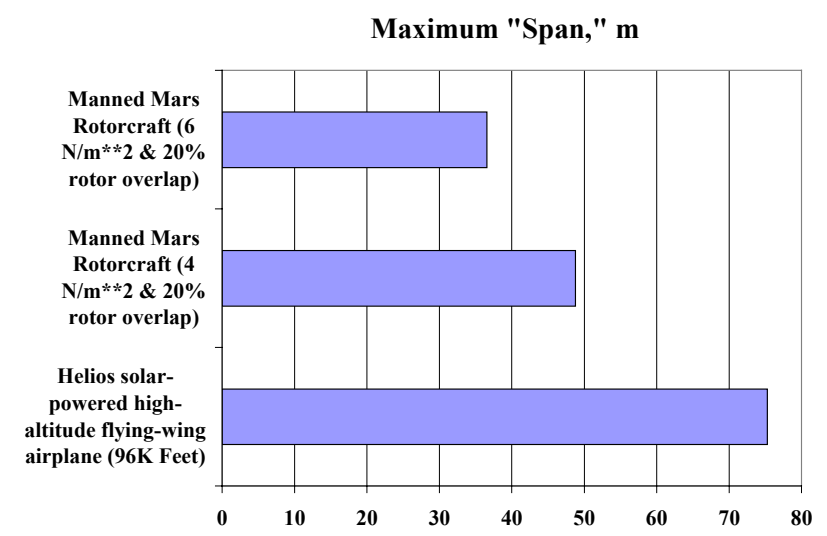

Fig. 9 - Comparative Sizes

Alternate rotorcraft configurations are potentially viable for manned Mars rotorcraft, but the coaxial tandem helicopter configuration results in one of the smallest vehicle planform areas. Table 4 summarizes some of the potential applications of manned Mars rotorcraft. Figures 10 and 11 provide initial power and range estimates for such a vehicle.

Table 4. Potential Manned Vehicle Applications

\section{- Scouting}

- Canyon excursions (to and from the base and crest of the canyon wall)

- Transport/placement of small science stations

- Transport/placement of small support depots for forward planning of ground treks

- Large specimen transport

- Drill-rig/excavator transport

- Emergency repair of remote-site equipment

The extremely large size of such a manned (or autonomous cargo) vehicle would require assembly on Mars. Additionally, inflatable, self-cured structures might well be required for the rotor blades, for example. Or, alternatively, the blades could be assembled from multiple spanwise sections (a similar, "hinged" approach was suggested in [16]).

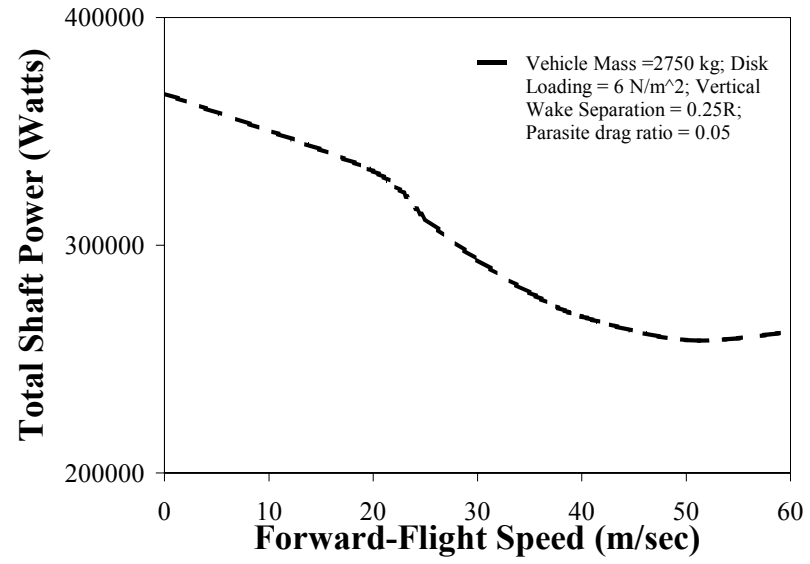

Fig. 10 - Notional Manned Rotorcraft Power Estimates as Function of Speed

Such a large, multi-rotor vehicle has significant rotor-torotor wake/aerodynamic interactions that affect the vehicle overall performance, both in hover and forward flight (Figs. 10-11). Insights from terrestrial coaxial and tandem helicopters aid in assessing the rotor-on-rotor interactions for this notional coaxial-tandem configuration, but more detailed work would be required to fully understand the aerophysics of this unique vehicle configuration.

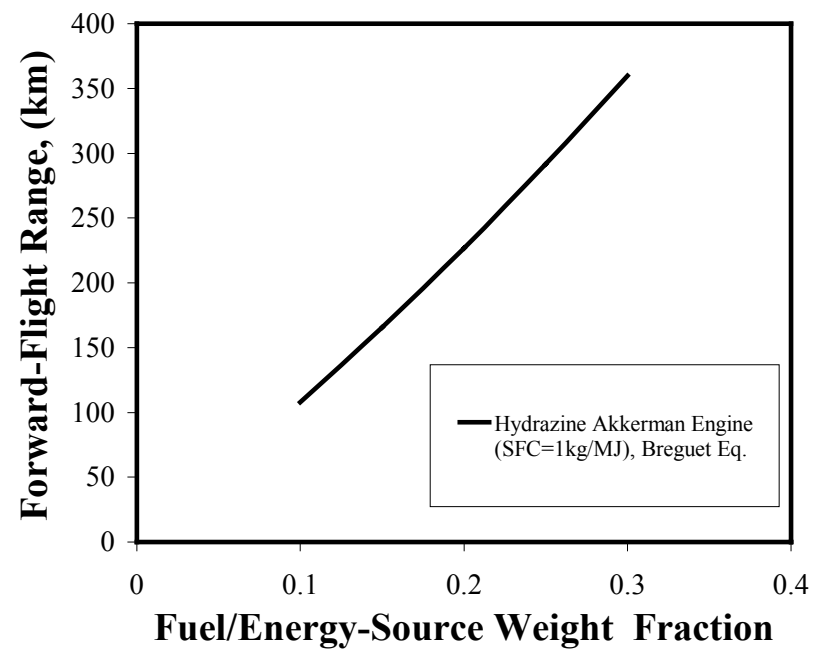

Fig. 11- Maximum Range Estimate (assumed cruise speed of $40 \mathrm{~m} / \mathrm{sec}$, with no hover/loiter time accounted for in initial estimates)

It is assumed that a manned rotary-wing vehicle would be powered by in-situ derived propellant and oxidizer (for example, methane and $\mathrm{O}_{2}$ ). The ISRU (In-Situ Resource Utilization), in turn, would be powered by the same nuclear reactor which powers the base camp electrical needs and the return-home ascent-vehicle in-situ propellant generation. 
One consideration that must be kept in mind is likely that fairly frequent hardware replacement, particularly for rotor blades, might be required for safe maintenance of the manned vehicles. Unfortunately, one of the consequences of achieving ultra-lightweight structural components may be a low tolerance to atmospheric dust erosion/coating and fatigue damage. Such high maintenance demands may place a heavy burden on the astronauts as well placing on high demand on replacement hardware stocks.

Piloting, or teleoperating, very large Mars rotorcraft will require the use of synthetic vision techniques. Only by this means will the pilot have adequate situational awareness during critical phases of the flight regime such as take-off, landing, and low altitude flight.

\section{The Large Versus the Many}

A prominent debate within the robotics community, as a whole, continues as to the question of the relative merits of small, simple, and numerous robotic systems working in concert to accomplish a goal, versus a few, large, and more sophisticated robots used to perform the same task. This same issue is equally applicable to Mars rotorcraft.

A qualitative benefit versus risk equation can be defined for MSS versus FCL (Many, Simple, Small versus Few, Complex, Large) robotic exploration mission trade-off analysis. Three assumptions are implied in this benefit/risk assessment: 1.lower levels of mobility are implied but not by definition required for smaller vehicles versus larger ones, 2 . approximately equivalent mission costs between the MSS and the FCL missions, and 3. approximately equivalent mission goals and objectives between the MSS and FCL robotic missions. A qualitative measure of mission "return" for a purely scientific endeavor can be defined by the relationship:

$$
\text { Mission Return } \equiv \frac{\text { Information Gathered }}{\text { Risk }}
$$

where

Information Gathered $=$
Number of sensors
X Measure of spatio - temporal dispersal of sensors
X Mean sophistication of sensors
X Number of different types of sensors
X Ability to interprete/adapt given past results
X Ability to verify results
X Ability to cross - correlate independent measurements

and the inverse of risk is

$$
\begin{aligned}
& \text { 1/Risk }= \\
& (1-\text { Mean probability of sensor failure }) \\
& \text { X Mean probability of sensor successful dispersal } \\
& \text { X Mean probability of communicating data back to Earth }
\end{aligned}
$$

Each of the key parameters can be initially defined in terms of subjective measures (such as giving a qualitative ranking of 0-10 for lowest and most of a given measure/metric). Alternatively, as more rigorous analysis and simulation are applied to the MSS versus FCL problem for a given mission scenario and cost (among others) constraint, then more quantitative expressions for these parameters can be implemented. One example of this potential quantification, is the measure of the spatio-temporal dispersal of sensors, which is denoted below by $\mathrm{D}$, where one quantitative measure of this parameter could be:

$$
D=\frac{1}{\left(1+\frac{\bar{V} \Delta t}{\bar{x}}\right)}
$$

where $\bar{V}$ is the mean sensor dispersal (and/or scanning) rate/velocity (over the whole of the mission), $\Delta t$ is the duration of the sensing/mission, and $\bar{x}$ is the mean initial spatial "seeding" of the sensors $(\bar{x}=0$ for a single sensor and, therefore, $\mathrm{D}=0$; for sensors greater than one, then the maximum distance length-scale between sensors is used). In general, though, MSS missions have certain advantages and disadvantages over FCL missions, and vice versa. For example, a large number of sensors is a key attribute of the MSS approach; further, the low-mobility (because of limited energy and range) of the MSS platforms can be partially offset by this large number of sensors/platforms in the "dispersal" qualitative metric. On the other hand, the high mobility $(\bar{V} \Delta t>>\bar{x})$ of the FCL platforms and their likely higher sophistication of sensors provide a counterpoint to the MSS approach.

Note that, in turn, the mean probability of successfully dispersing sensors has two elements to it: first, failure of the dispersal mechanisms/platforms to distribute the sensors, and, second, failure of the search and find approach to find the nominal locations to disperse the sensors. In this regards, Eq.1 incorporates robotic exploration issues ranging from platform robustness and capability all the way to intelligent systems algorithmic design/definition. Equation 1 can be applied to not only aerial explorers but any other robotic/sensor asset used for planetary exploration. For example, stationary sensors (deployed en masse during EDLS entry can have a information gathering contribution due to a large spatial (though immobile after ground contact) distribution of multiple sensors. Such an approach, if having a large enough dispersal pattern and 
sufficiently large quantities of sensors could potentially match or exceed the information gathering potentiality of more mobile robotic exploration assets.

Figure 12 illustrates the MSS versus FCL issue for Mars rotorcraft. For large rotorcraft, greater size payloads can be carried - perhaps even transporting assets such as rovers. For very small rotorcraft, such vehicles could be deployed by a robotic carrier - in this case a large rover. This example shows, in part, the range of mission possibilities when the "large versus many" issue is considered for Mars rotorcraft.

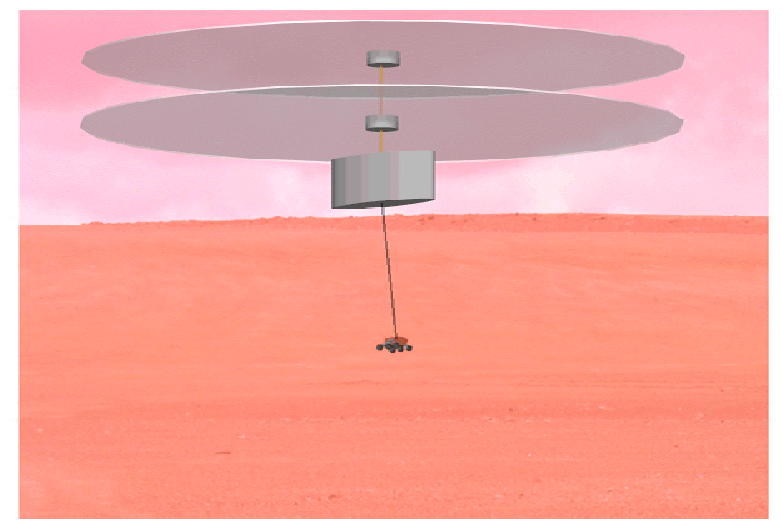

(a)

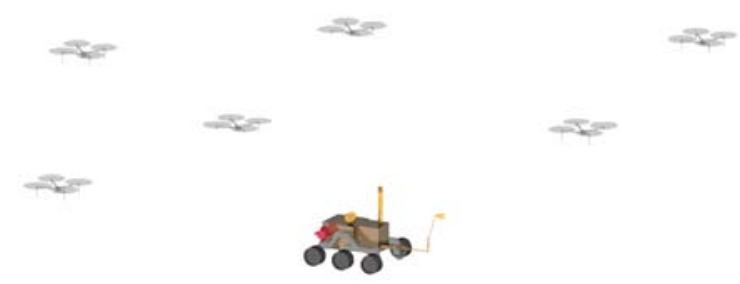

(b)

Fig. 12 - Illustration of the Large vs. Many Scenario: (a) large, complex, multi-rotor rotorcraft and (b) a swarm of very small rotorcraft

One side benefit of employing larger Mars rotorcraft to conduct mission tasks is that the rotary-wing aerodynamics of these larger vehicles approach more conventional regime of terrestrial helicopters. Figure 13 shows the tip Reynolds number trend as a function of rotor size (for various rotor solidity values - ratio of blade area to disk area -- and tip Mach numbers). The tip Reynolds numbers for very large Mars rotorcraft $\left(\mathrm{Re}_{\mathrm{Tip}}\right)$ begin to approach the rough magnitude of (small) scaled rotors tested in hover and wind tunnel tests.

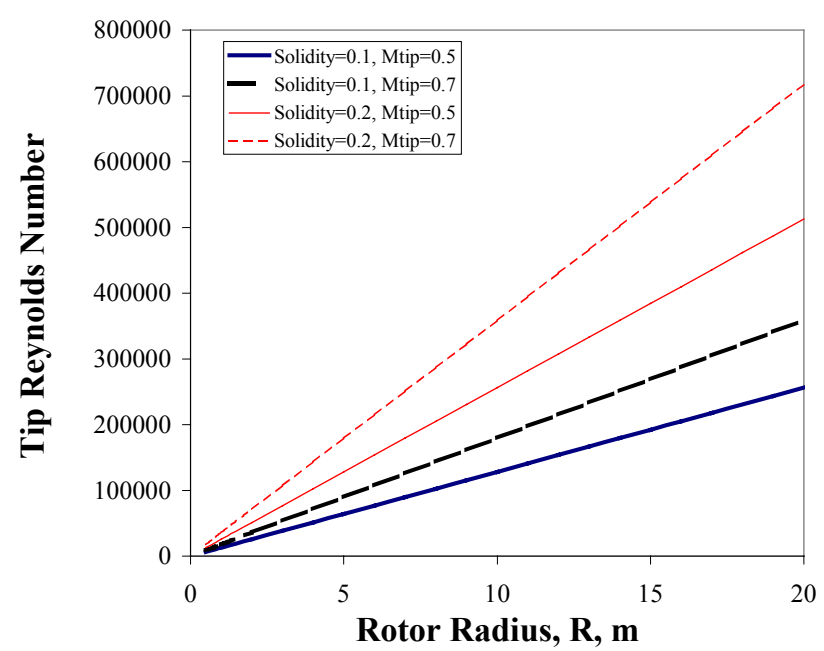

Fig. 13 - Trending of Reynolds number with Rotor Size (Assumed Four-Bladed Rotors)

Early advocates of the MSS approach to vertical lift planetary aerial vehicles were the "Mars mesicopter" [21] and the Mars "entomopter" [30] concepts. Other than this early pioneering work, limited examination has been given to this very small vehicle class. In part, though, this limited body of work reflects the difficulty of providing adequate payload/range capacity in a very small vehicle packages.

The "large versus many" problem - as applied to a wide range of robotic task domains/applications -- deserves more attention in the future, not only for Mars rotorcraft but other planetary robotic assets as well.

\section{OTHER Robotic MisSIONS}

The new paradigm of "rotorcraft as robots" opens up a considerable number of options as to robotic-assisted exploration of Mars. To fully achieve the potential of small robotic rotorcraft explorers it will be necessary to not only fly autonomously over the planetary surface, however low and slow it may be, but once upon the ground the rotorcraft must interact with the surface - such as acquiring soil/rock samples, placing sensors and other devices. Reaching out and doing something while on the ground at remote sites is a key attribute of small robotic Mars rotorcraft. Recent research at NASA Ames is drawing heavily on bioinspiration to address some of these fundamental design questions as to "rotorcraft as robots" [2-8].

Also driving the new design space for small Mars rotorcraft is the inherent need to have these explorers interact in robotic symbiosis with rovers, landers, and other robotic systems. A Mars rotorcraft, in a purely robotic mission, will need to be autonomously recharged/refueled, transfer samples for more 
detail in-situ analysis, and be otherwise maintained. Therefore, automation in a system of systems (or a robotic ecology) context is crucial for the success of purely robotic Mars rotorcraft missions [4-6].

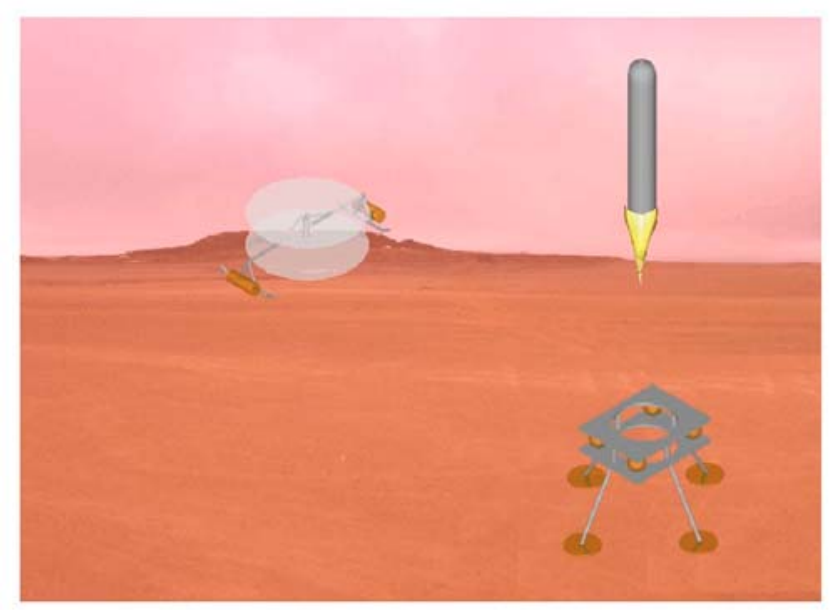

Fig. 14 - Rotary-Wing Mobility Coupled With Sample Collection and Return to Earth

Finally, new, hybrid modes of transport might well be entailed for Mars rotorcraft. Among these hybrid vehicles there might be rotary-wing platforms that can skim, skip, and jump, in addition to performing powered level flight. Additionally, combined mother- and daughter-ship vehicles may also provide unique flexibility for exploration [24].

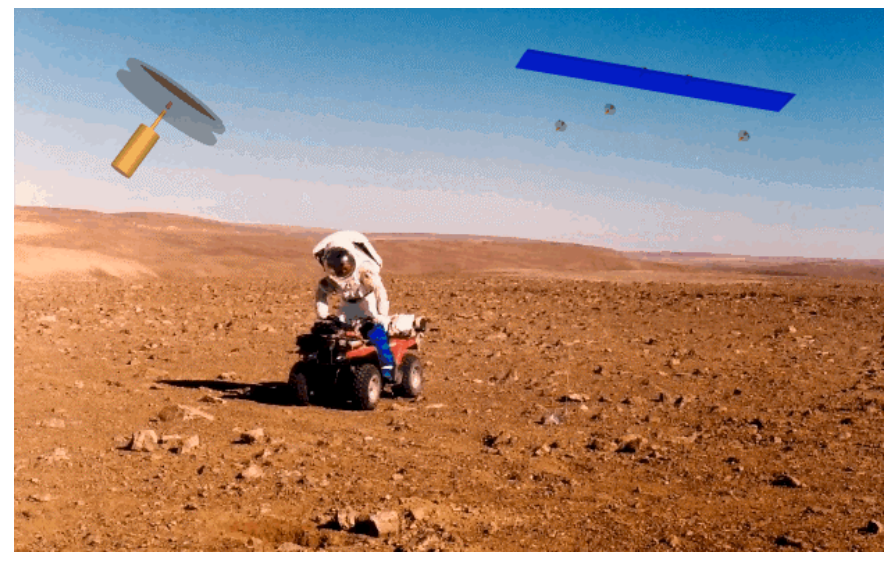

Fig. 15 - Hybrid Vehicles/Robots

A typical mission profile for an "aerial surveyor" hybrid vehicle is illustrated in Fig. 16. In this notional concept, the flying-wing vehicle's propulsion pods perform dual service as vertical flight (coaxial rotary-wing) drones. As the mission progresses, subsequent to the vehicle's fixedwing take-off, these pods/drones are released in mid-air and drop/auto-rotate to the ground. Half the propulsion pods (symmetrically across the span of the flying-wing) are released by the mid-point of the mission. Upon this dissemination/distribution of the pods/drones, the flyingwing vehicle returns to base camp. Upon release from the "aerial surveyor" mothership, the drones auto-rotate to the ground and then with limited rotary-wing mobility investigate the surface terrain.

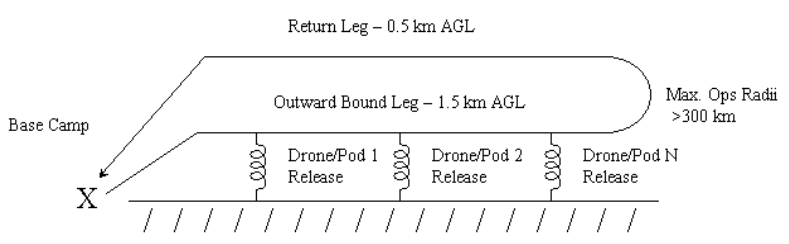

Fig. 16- Aerial Surveyor Mission Profile

\section{SMart Rotorcraft Field Assistants}

Terrestrial field science demonstrations at Mars-analog sites - such as Haughton Crater, Devon Island, Canada --- can be considered a prelude to the human exploration of Mars, particularly with the examination of the technology challenges of implementing "smart rotorcraft field assistants." Preliminary research has begun in this area [6], but considerably more work needs to be performed.

If the conduct of high-quality science can not be accomplished at terrestrial extreme environment sites with robotic field assistants, it is highly unlikely such science can be conducted on another planet. Therefore, it is crucial to expand upon the work to date on human and robotic technology, and science, investigations at Mars-analog sites.

In this regard, smart rotorcraft field assistants represent one application trend with respect to micro air vehicles and aerial robot development [2].

\section{The Future}

The path to developing large Mars rotorcraft is first through terrestrial field assistants and then small, purely robotic, Mars missions. Figure 17 is a notional roadmap for developing such a technology/mission capability for Mars rotorcraft. 


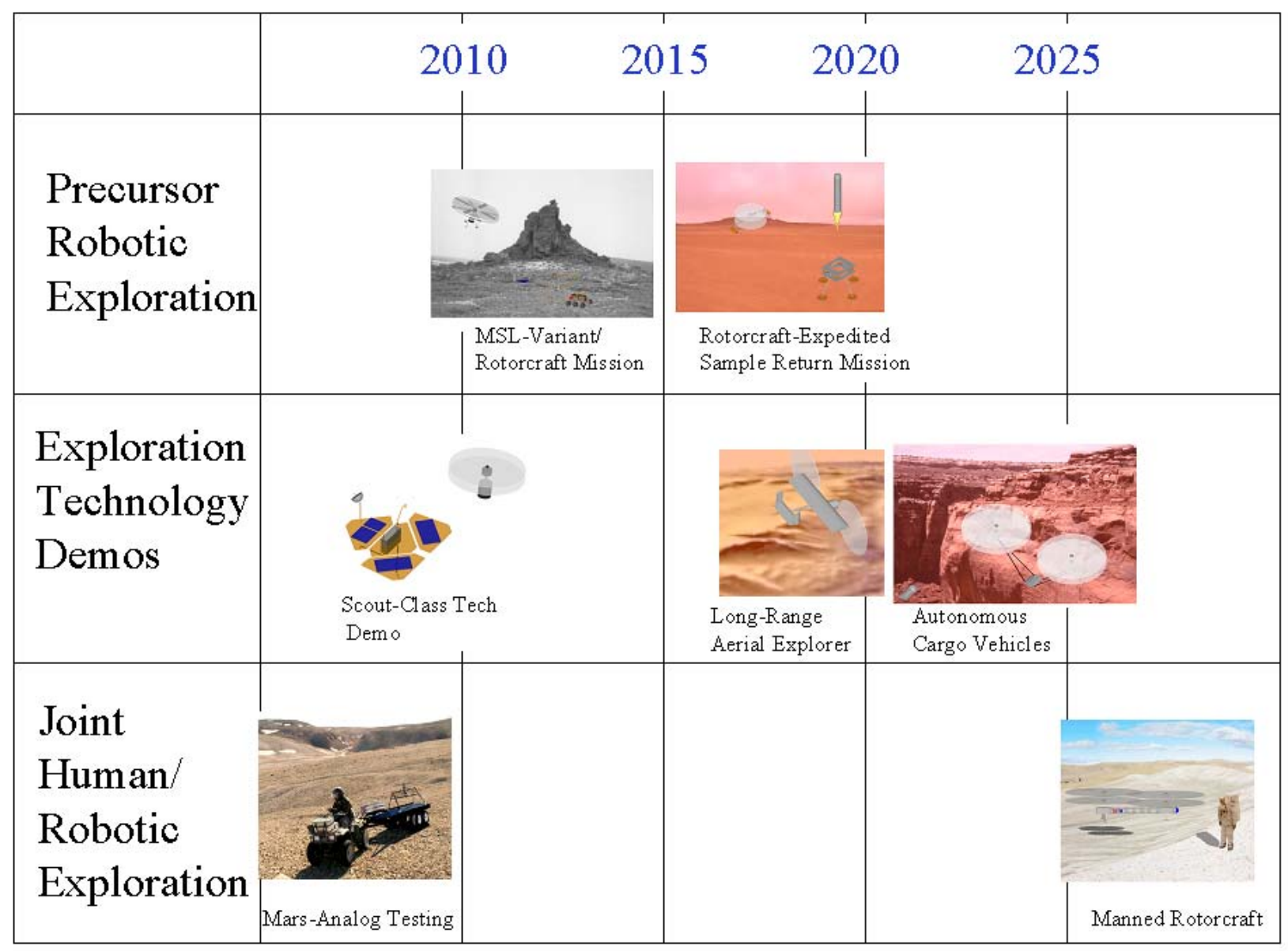

Fig. 17 - Notional Technology/Mission Capability Roadmap

\section{Concluding Remarks}

Though considerable progress has been made with regards to Mars rotorcraft design, more work lies ahead. The development of Mars rotorcraft, and other planetary aerial vehicles, will entail, among other things, continued creative application and modification of existing weight estimation methods, as well as the development of new analysis techniques and structural design approaches. It is important to recognize, though, that no new fundamental insights into physics and/or radically new technologies are required for the development of such vehicles. The development of fixed- and rotary-wing planetary aerial vehicles is an engineering challenge worthy of the nation that revolutionized the world over one hundred years ago with the achievement of first flight on this planet, our Earth. Whether or not a manned rotorcraft will ever fly on Mars is one of open speculation. However, small to mid-size robotic Mars rotorcraft, both in purely robotic missions and working in concert with human explorers, will no doubt one day be developed.

\section{BIOGRAPHY}

Mr. Young has worked at NASA Ames Research Center in the area of rotorcraft research for the past twenty-two years. $\mathrm{He}$ has worked on several largescale tiltrotor/rotorcraft experimental programs in the National Aerodynamics Complex at NASA Ames. Mr. Young is currently leading several

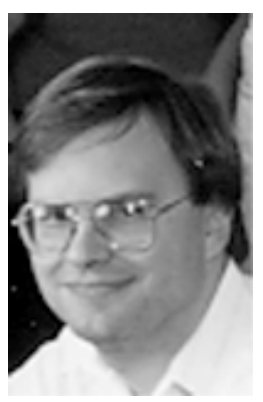
advanced rotorcraft technology efforts at NASA Ames, including the study of advanced vehicle design, vertical lift planetary aerial vehicles and Mars rotorcraft, autonomous system technology applied to uninhabited aerial vehicles (UAV). 


\section{REFERENCES}

[1] Aiken, E.W., Ormiston, R.A., and Young, L.A., "Future Directions in Rotorcraft Technology at Ames Research Center," American Helicopter Society $56^{\text {th }}$ Annual Forum Proceedings, International, Virginia Beach, VA, May 2-4, 2000.

[2] Young, L.A., Aiken, E.W., Johnson, J.L., Demblewski, R., Andrews, J., and Klem, J., "New Concepts and Perspectives on Micro-Rotorcraft and Small Autonomous Rotary-Wing Vehicles," AIAA 20 $0^{\text {th }}$ Applied Aerodynamics Conference, St Louis, MO, June 24-27, 2002.

[3] Plice, L., Pisanich, G., Lau, B., and Young, L.A., "Biologically Inspired 'Behavioral' Strategies for Autonomous Aerial Explorers on Mars," IEEE Aerospace Conference, Big Sky, MT, March 2003.

[4] Plice, L., "Robot Economy," Robosphere 2002: Workshop on Self-Sustaining Robot Ecologies, NASA Ames Research Center, Moffett Field, CA, November 2002.

[5] Pisanich, G. and Young, L.A., "An Aerobot Ecology," Robosphere 2002: Workshop on Self-Sustaining Robot Ecologies, NASA Ames Research Center, Moffett Field, CA, November 2002.

[6] Young, L.A., Aiken, E.W., Gulick, V., Mancinelli, R., and Briggs, G.A., "Rotorcraft as Mars Scouts," 2002 IEEE Aerospace Conference, Big Sky, MT, March 916, 2002.

[7] Pisanich, G., Young, L.A., Ippolito, C., Plice. L., Lau, B., and Lee, P., "Initial Efforts towards MissionRepresentative Imaging Surveys from Aerial Explorers," SPIE (International Society of Optical Engineers) Electronic Imaging Conference, San Jose, CA, January 2004.

[8] Pisanich, G., Ippolito, C., Plice, L, Young, L., and Lau, B., "Actions, Observations, and Decision-Making: Biologically Inspired Strategies for Autonomous Aerial Vehicles," AIAA Aerospace Sciences Conference, Reno, NV, January 2004.

[9] Betz, A., "The Ground Effect on Lifting Propellers," NACA TM \# 836, August 1937.

[10] O'Bryan, T.C., "Considerations of the Effect of VTOL Downwash on the Ground Environment," NASA Conference on V/STOL Aircraft, pgs. 261-268, January 1960.

[11] Kuhn, R.E., "An Investigation to Determine Conditions Under Which Downwash from VTOL Aircraft Will Start Surface Erosion from Various Types of Terrain," NASA TN D-56, September 1959.
[12] Metzger, S.M., "Feeding the Mars Dust Cycle; Surface Dust Storage and Dust Devil Entrainment," The Fifth International Conference on Mars, LPI-Contrib-972, July 1999.

[13] Leovy, C., "Weather and Climate on Mars," Nature, Vol. 412, Macmillan Magazines, Ltd., pgs. 245-249, July 12, 2001.

[14] White, B., "Laboratory Simulation of Aeolian Sand Transport and Physical Modeling of Flow Around Dunes," Annuals of Arid Zone, September 1996.

[15] Thompson, B., "Full Throttle to Mars," Rotor \& Wing, Phillips Business Information, LLC, Potomac, MD, March 2001.

[16]Datta, A, Roget, B., Griffiths, D., Pugliese, G., Sitaraman, J., Bao, J., Liu, L., and Gamard, O., "Design of the Martian Autonomous Rotary-Wing Vehicle," AHS Specialist Meeting on Aerodynamics, Acoustics, and Test and Evaluation, San Francisco, CA, January 2002.

[17] Stepniewski, W.Z. and Shinn, R.A., "Soviet Vs. U.S. Helicopter Weight Prediction Methods," American Helicopter Society $39^{\text {th }}$ Annual Forum Proceedings, St. Louis, MO, May 9-11, 1983.

[18] Stepniewski, W.Z., "Some Weight Aspects of Soviet Helicopters," American Helicopter Society $40^{\text {th }}$ Annual Forum Proceedings, Arlington, VA, May 16-18, 1984.

[19]Zubrin, R., "Methods for Achieving Long Range Mobility on Mars," $28^{\text {th }}$ AIAA, SAE, ASME, and ASEE Joint Propulsion Conference, AIAA Paper 923862, Nashville, TN, July 6-8, 1992.

[20] Sivier, K.R. and Lembeck, M.F., "Marsplane Revisited," AIAA, AHS, and ASEE Aircraft Design, Systems, and Operations Meeting, AIAA Paper 884412, Atlanta, GA, September 7-9, 1988.

[21] Kroo, I. and Kunz, P., "Development of the Mesicopter: A Miniature Autonomous Rotorcraft," American Helicopter Society (AHS) Vertical Lift Aircraft Design Conference, San Francisco, CA, January 2000.

[22] Raymer, Daniel, Aircraft Design: a Conceptual Approach, $3^{\text {rd }}$ Edition, AIAA Education Series, American Institute of Aeronautics and Astronautics, Reston, VA, 1999.

[23]Akkerman, J.W. "Hydrazine Monopropellant Reciprocating Engine Development" NASA Conference Publication 2081, $13^{\text {th }}$ Aerospace Mechanisms Conference, Proceedings of a Symposium held at Johnson Space Center, Houston, TX, April 26-27, 1979.

[24] Young, L.A., et al, "Smart Rotorcraft Field Assistants for Terrestrial and Planetary Science," 2004 IEEE Aerospace Conference, Big Sky, MT, March 2004. 
[25] Young, L.A., et al, "Engineering Studies into Vertical Lift Planetary Aerial Vehicles," AHS International Meeting on Advanced Rotorcraft Technology and Life Saving Activities, Utsunomiya, Tochigi, Japan, November 11-13, 2002.

[26] Young, L.A., et al, "Experimental Investigation and Demonstration of Rotary-Wing Technologies for Flight in the Atmosphere of Mars," American Helicopter Society $58^{\text {th }}$ Annual Forum Proceedings, Montreal, Canada, June 11-13, 2002.

[27] Young, L.A. and Aiken, E.W., "Vertical Lift Planetary Aerial Vehicles: Three Planetary Bodies and Four Conceptual Design Cases," $27^{\text {th }}$ European Rotorcraft Forum, Moscow, Russia, September 11-14, 2001.

[28]Hoerner, S.F., Fluid Dynamic Drag, Self-Published, 1965.

[29] Johnson, W., Helicopter Theory, Princeton University Press, 1980.

[30] Michelson, R.C., and Navqi,, M.A., "Extraterrestrial Flight (Entomopter-Based Mars Surveyor)," Low RE Aerodynamics on Aircraft Including Applications in Emerging UAV Technology, RTO-AVT von Karman Institute for Fluid Dynamics Lecture Series, November 24-28, 2003.
[31] Anderson, S.B., "An Overview of V/STOL Aircraft Development," AIAA Paper 83-2491, October 1983.

\section{APPENDiX A - ANALYSIS/Discussion On SMall TO MID-SIZE MARS ROTORCRAFT}

It is not easy at first to conceptualize how a Mars rotorcraft might be feasible. The very thin, cold, and predominately carbon-dioxide atmosphere of Mars makes it a very daunting task. The following thought experiment hopefully aids in easier conceptualization of Mars rotorcraft design considerations.

Figure 18 illustrates the factors/constraints that need to be "balanced out" in order to achieve rotary-wing hover and forward-flight in the atmosphere of Mars. A key consideration in achieving such flight the development of ultra-lightweight structures for rotor components, in particular. Other important design considerations include unique aerodynamic operating conditions for the rotors, propulsion systems that don't require intake and combustion of oxygen, and as yet unattained high-levels of vehicle (and associated equipment) autonomy.

\begin{tabular}{l}
\hline Weighing Things Down - \\
- Mars nominal surface atmospheric density \\
$\sim 1 \%$ of Earth's \\
- Mars atmospheric speed of sound $70-75 \%$ \\
of Earth's \\
- Mars atmosphere is $>95 \%$ carbon dioxide; \\
conventional rotorcraft engines do not work \\
- Mars rotorcraft blade airfoils operate in \\
compressible, low-Reynolds number flow \\
conditions; profile drag much higher for \\
these rotors \\
- Mars rotorcraft blades have to be much \\
larger than conventional rotorcraft
\end{tabular}

\begin{tabular}{|l|}
\hline Achieving Flight - \\
- Mars gravity $38 \%$ of Earth's \\
- Reducing blade mass to $5-10 \%$ of \\
conventional rotor blade mass \\
- Typical Mars rotorcraft payload $<10 \% \mathrm{GW}$ \\
versus $25-40 \%$ for conventional rotorcraft \\
- Tip speeds kept within engineering \\
experience, I.e. less than tip Mach of 0.7 \\
- Electric and hydrazine reciprocating engine \\
propulsion has been demonstrated \\
- Structural weight can be significantly reduced \\
over conventional rotorcraft: all-composite \\
materials and lower inherent aero loading
\end{tabular}

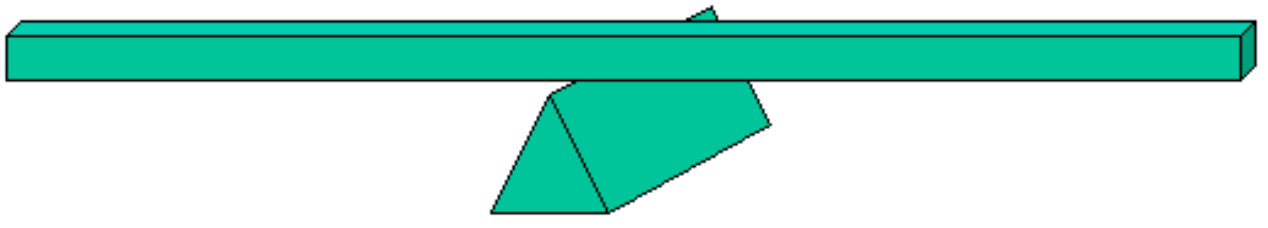

Fig. 18 - Balancing out the "Performance Scales" for Mars Rotorcraft 
Past work has focused on rotor aerodynamics, vehicle autonomy, and propulsion. The major thrust of this paper is to examine in more detail the weight trends for Mars rotorcraft. However, before proceeding to the weight trend analysis, a couple of comments should be presented as to the aerodynamic analysis implicit in the presented performance results and rotor sizing trends noted in this paper.

First, the airfoil mean profile drag characteristics used in this paper to estimate rotor performance was based on the following set of approximate expressions. More refined airfoil characteristics would be required for the detailed design of Mars rotors.

$$
\begin{aligned}
& \mathrm{C}_{\mathrm{d} 0} \approx\left\{\begin{array}{l}
\mathrm{a} \\
\mathrm{b} R e_{\mathrm{Tip}}^{-1 / 5} \\
\mathrm{c}
\end{array}\right. \\
& \text { for } \operatorname{Re}_{T i p}<10^{5} \\
& 10^{5}<R e_{T i p}<7.5 \times 10^{5} \\
& R e_{\text {Tip }}>7.5 \times 10^{5} \\
& \text { where } \\
& a \approx 0.03 \\
& \mathrm{~b}=0.118\left(1+2 \mathrm{t} / \mathrm{c}+60(\mathrm{t} / \mathrm{c})^{4}\right) \\
& c \approx 0.0087
\end{aligned}
$$

Second, the bulk of rotor sizing trends presented in this paper assume only small to modest blade root cut-outs $\left(r_{c} / R\right.$ $<0.25$ ). Early work on Mars rotors, however, assumed fairly large blade root cut-outs to provide for the capacity of blade telescoping action (in conjunction with blade folding) to arrive at compact stowed configurations for in-space transport of the Mars rotorcraft. There is an induced power penalty for this rotor storage/stowage approach. The effective induced power constant (with influence of large blade root cut-out included), $\mathrm{k}_{\mathrm{e}}$, is proportional to the expression

$$
\mathrm{k}_{\mathrm{e}} \approx\left(\sqrt{\frac{1-\mathrm{r}_{\mathrm{c}} / \mathrm{R}}{1+\mathrm{r}_{\mathrm{c}} / \mathrm{R}}}+\frac{\mathrm{r}_{\mathrm{c}} / \mathrm{R}}{1-\mathrm{r}_{\mathrm{c}} / \mathrm{R}}\right) \mathrm{k}
$$

Where $\mathrm{k}$ is the induced power constant without a significant blade root cut-outs. This expression results the transition of the rotor induced power characteristics from that of actuator-disks to finite aspect-ratio (fixed) wing-like characteristics. The expression is agreement with both experimental and CFD results for the rotors with large blade root cut-outs.

Finally, the rotor-on-rotor performance interactions (in hover and forward-flight) for the coaxial and tandem (and hybrid coaxial-tandem) helicopter configurations are estimated based on first-order analyses from $[25,29]$.
Though the primary focus of this paper is on conceptual design studies and weight sizing analysis, a key emphasis of the NASA Ames Mars rotorcraft work has been on prototyping and fundamental aerodynamics/aeromechanics [25-26]. As a part of this prototyping work has been the development (and test and analysis) of a Mars-representative isolated rotor. The next step in this prototyping effort is the development of a complete vehicle. The MARTA (Marsanalog rotorcraft test article) prototype is currently in the early stages of design. A key design feature of MARTA will be the testing of a new type of rotor system (a second generation rotor specifically tailored for small Mars rotorcraft, as compared to the initial isolated Mars rotor tested earlier in the project) on a coaxial helicopter platform configuration. Additionally, small terrestrial surrogate rotary-wing vehicles, such as the "smart rotorcraft field assistant (SRFA)," have also been developed and flight tested (Fig. 19). There is a considerable parallelism and dual-use application for planetary and terrestrial extreme environment field science. This parallelism continues to be exploited by the research outlined in this paper and earlier work [6].

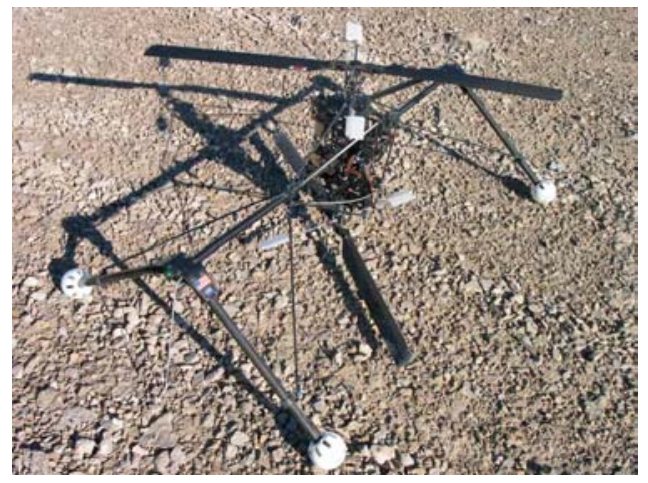

Fig. 19 - Proof-of-Concept SRFA

The first MARTA test article design will not embody the features allowing it to collapse (fold/telescope) into a form suitable for stowage and deployment.

Very small Mars rotors will have low aspect-ratio blades. Matching blade sets will in general be designed as continuous structures - to minimize hub attachment hardware weight penalties. This will tend to dictate rotors with evennumbered blade counts. Work with low Reynolds rotors (albeit under incompressible flow conditions) has supported the use of simple cambered, circular-arc flat-plate airfoils for rotors operating at tip Reynolds numbers less than 50,000. Such (incompressible) low Reynolds number rotors have hover figures of merit ranging between 0.35 and 0.5 , which is considerably less than terrestrial rotors, but probably acceptable in light of weight savings derived from the simplified blade structural design. To lighten such blades as much as possible, as well as providing for chordwise center-of-gravity balance, airfoil trailing edge cutout-panels 
with Mylar covering the blade upper surface can be implemented (Fig. 20) with very little, if any, performance impact.

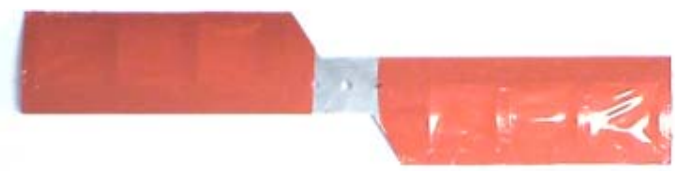

(a)

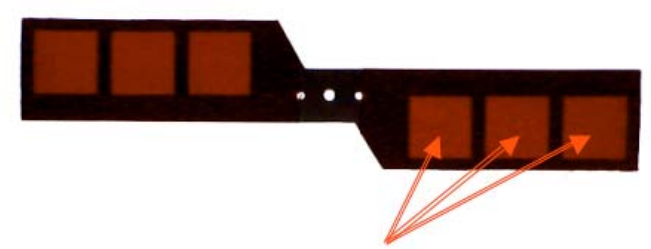

Mylar covered (upper surface only) cutout-panels for lightening \& c.g. balancing

(b)

Fig. 20 - Very Small (in terms of mass) Mars Rotors: (a) planform and (b) back-lighted views

As the tip Reynolds number increases to over 50,000, then true laminar-flow airfoil shapes are required - such as the Eppler 387 employed on the Mars baseline rotor [26]. For very large Mars rotors, the tip Reynolds numbers approach the magnitude seen for "small-scaled" terrestrial rotors, i.e., 500,000 or greater. In this regards, rotor/airfoil aerodynamic design will be relatively more straightforward for the larger Mars rotors. Unfortunately, the structural and dynamic design of this larger class of Mars rotors will still be very challenging.

Weight trends for these smaller (less than or equal to approximately $20 \mathrm{~kg}$ ) Mars rotorcraft are based in part on data summarized in $[2,26,27]$. In part derived from the [2, 27] data, the following weight equations (Eqs. 5-11) apply for very low Reynolds number, electric propulsion rotorwing platforms.

The blade weight equation (assuming the use of cambered flat-plate blade airfoils) is given by the expression

$$
m_{\text {blade }}(\chi) \approx A_{F}\left[m_{\text {Struct }}(\chi)+m_{\text {Mylar }}\right]
$$

and

$$
\begin{aligned}
m_{\text {Mylar }}= & \frac{1}{2} \rho_{\text {Mylar }} t_{\text {Mylar }}\left(R_{o p}-R_{i p}\right) \\
\cdot & {\left[\left(S(R)+\chi_{L E} c(R)\right)+\left(S\left(r_{c}\right)+\chi_{L E} c\left(r_{c}\right)\right)\right] }
\end{aligned}
$$

$$
m_{\text {Struct }}(\chi)=\rho_{G E} t_{G E}[A+B]
$$

$$
\begin{aligned}
A= & \frac{1}{2}\left(S\left(r_{c}\right)+S(R)\right)\left(R-r_{c}\right) \\
& -\frac{1}{2}\left(\chi_{T E}-\chi\right)\left(c\left(R_{i p}\right)+c\left(R_{o p}\right)\right)\left(R_{o p}-R_{i p}\right) \\
& +c_{S p a r} r_{c}
\end{aligned}
$$

$$
B=\frac{1}{2} n_{w e b} \Delta r_{w e b}\left(\chi_{T E}-\chi\right)\left(c\left(R_{i p}\right)+c\left(R_{o p}\right)\right)
$$

with

$$
c(r)=c_{\text {Tip }}\left[1+\left(\frac{1}{\text { taper }}-1\right)\left(\frac{r-R}{r_{c}-R}\right)\right]
$$

$$
h(r)=\text { camber } \cdot c
$$

$$
\begin{gathered}
R_{\text {arc }}(r)=\frac{c(r)^{2}+4 h(r)^{2}}{8 h(r)} \\
\theta(r)=2 \arcsin \left(\frac{c(r)}{2 R_{\text {arc }}(r)}\right) \\
S(r)=R_{\text {arc }}(r) \theta(r)
\end{gathered}
$$

where $A_{F}$ is an adjustment factor, and typically $A_{F}=1.10$ for non-folded/non-telescoping blades $\mathrm{A}_{\mathrm{F}}=1.30$ for folded/telescoping blades. Note $\rho_{\text {Mylar }}$ and $t_{\text {Mylar }}$ and $\rho_{\mathrm{GE}}$ and $t_{\mathrm{GE}}$ are the density and thickness of Mylar and graphite epoxy layers in the cambered circular-arc flat-plate airfoil blade layup. The blade radial stations, $\mathrm{R}, \mathrm{r}_{\mathrm{c}}, \mathrm{R}_{\mathrm{ip}}$, and $\mathrm{R}_{\mathrm{op}}$ are the blade, blade-root, inner and outer cutout panels dimensional radii. The parameters $\chi, \chi_{\mathrm{TE}}$, and $\chi_{\mathrm{LE}}$ are the dimensional chordwise stations (measured from the local airfoil crosssection leading edge) for the forward location of the panel cutouts, aft termination of the cutout, and the forward location of the bonding of the Mylar sheet to the lower surface of the airfoil. Finally, $\mathrm{n}_{\mathrm{web}}$ and $\Delta \mathrm{r}_{\mathrm{web}}$ are the number and spanwise dimension of the "webs" between each blade cutout panels. (Refer to Fig. 21 for details.)

Further, where, to the first-order, the following chord-wise center-of-gravity balance constraint, quadratic in nature, 
holds (given the assumption that the flat-plate airfoil camber is small)

$$
\chi<\frac{-b_{0}+\sqrt{b_{0}^{2}-4 a_{0} c_{0}}}{2 a_{0}}
$$

where

$$
\begin{gathered}
a_{0}=\frac{1}{2} \rho_{G E} t_{G E} \\
b_{0}=-\frac{1}{4} c \rho_{G E} t_{G E} \\
c_{0}=\frac{1}{2}\left(\frac{1}{2} c-\chi_{T E}\right) \chi_{T E} \rho_{G E} t_{G E} \\
+\frac{1}{4} c^{2} \rho_{\text {Mylar }} t_{M y l a r}+\frac{1}{4} c^{2} \rho_{G E} t_{G E} \\
-\frac{1}{2}\left(\frac{1}{2} c-\chi_{L E}\right) \chi_{L E} \rho_{\text {Mylar }} t_{M y l a r}
\end{gathered}
$$

(6a-d)

The above expression should be considered minimum criterion for aeroelastic stability (to place the airfoil centerof-gravity on the airfoil quarter-chord). Note that additional tip weights will be required to the leading-lower lower surface in order to counterbalance the blade structural "webs." Shifting the center-of-gravity even further forward may well be required to account for camber effects and the variance of the airfoil effective aerodynamic center of pressure from the quarter-chord.

The remaining key weight/mass equations are as follows (assuming electric propulsion and RC-type servos).

The rotor hub weight is estimated by

$$
m_{\text {Hub }} \approx a \sqrt{N_{\text {Blade }}}\left(\frac{S_{y} / \gamma_{G E}}{S_{y} / \gamma}\right) m_{G W}
$$

where $a=0.02$ given [2] data trends and implicit accounting for relative scaling of hub material (composite construction is assumed as the baseline material) and blade tip speeds. (Note that this expression is considerably different from more conservative than -- the Appendix B larger rotorcraft methodologies.)

The flight control weight estimate (includes both actuators, mechanical control system hardware, and flight computer/avionics is given by

$$
m_{f c}\left(m_{G W}\right) \approx \mathrm{g}\left(m_{G W}\right)+\mathrm{h}\left(m_{G W}\right)
$$

with

$$
\begin{aligned}
& g\left(\mathrm{~m}_{\mathrm{GW}}\right)= \\
& u\left(20-\mathrm{m}_{\mathrm{GW}}\right)\left[\mathrm{a}+\mathrm{b} u\left(\mathrm{~m}_{\mathrm{GW}}-5\right)+\mathrm{c} u\left(\mathrm{~m}_{\mathrm{GW}}-10\right)\right] \\
& +\mathrm{dm}_{\mathrm{GW}} u\left(\mathrm{~m}_{\mathrm{GW}}-20\right)
\end{aligned}
$$

$$
\mathrm{h}\left(m_{G W}\right) \approx\left[f_{1}+f_{2} \ln \left(m_{G W}\right)\right]\left(\frac{S_{y} / \gamma_{\text {Plastic }}}{S_{y} / \gamma}\right)
$$

Note that the $u\left(\mathrm{x}-\mathrm{x}_{0}\right)$ is the step-function; for $\mathrm{x} \geq \mathrm{x} 0$ then $u(\mathrm{x}-$ $\left.\mathrm{x}_{0}\right)=1$ for $\mathrm{x}<\mathrm{x} 0$ then $u\left(\mathrm{x}-\mathrm{x}_{0}\right)=0$. Further, $\mathrm{a}=0.09$ (fixed weight that provides for radio receiver and basic trim mixer circuit board capability). An onboard camera will be required for somewhat larger (operational versus proof-ofconcept vehicles), and so $b=0.109$. To add an autopilot and mission computer (PC-104 single-board computer), $\mathrm{c}=0.08$. Maximum assumed fixed weight of mission computer, avionics, and guidance/navigation sensors (with redundancy), gives $\mathrm{d}=0.1$. Note $\mathrm{m}_{\mathrm{GW}}$ denotes the mass associated to the take-off gross weight of the vehicle. Note that the function $h\left(\mathrm{~m}_{\mathrm{GW}}\right)$ defines the mechanical system components of the flight control system; where $f_{1}=0.2$ and $\mathrm{f}_{2}=0.14$ from [2] data, and a special correction factor based on the specific strength of the materials is added into the weight term. Use of graphite epoxy composite materials instead of the plastic materials typical of radio-controlled electric helicopters significantly brings down the flight control mechanical component weights.

The drive weight is given by

$$
m_{\text {Drive }}\left(P_{\text {Hover }}\right) \approx a P_{\text {Hover }}
$$

where $\mathrm{a}=0.432$ from [2] data (based on limited radiocontrolled, electric helicopter data). The drive mass, $\mathrm{m}_{\text {Drive, }}$ for a vehicle with electric propulsion includes the motor(s), solid-state controller(s) and electric harnesses. This is a key difference in weight equations between this methodology and that of Appendix B. In the case of Appendix B, the equations are derived for a fuel-powered propulsion system and so $m_{\text {Drive }}$ is only roughly equivalent to elements of the weights estimated therein for elements of the drive-train, fuel system and propulsion system. The $\mathrm{P}_{\text {Hover }}$ term in the above expression is the rotor shaft power required for " $1-G$ " hover.

$$
m_{\text {motor }}\left(P_{\max }\right) \approx a P_{\max }
$$

where $\mathrm{a}=0.4$ and $\mathrm{P}_{\max }$ in $\mathrm{kW}[27]$. 
The small Mars rotorcraft fuselage weight is given by

$$
\begin{aligned}
& m_{F}\left(m_{G W}, t / R\right) \approx \\
& \operatorname{am}_{G W}\left(\frac{\gamma}{\gamma_{\text {Plastic }}}\right)\left\{b+(1-b) u\left(2-\frac{t}{R}\right)\left[1-0.56 u\left(\frac{t}{R}-0.2\right)\left(\frac{t}{R}\right)\right]\right\}
\end{aligned}
$$

where $a=0.125$ based on [2] data and $b=0.25$. Note that there is a strong coupling of the fuselage weight with the landing gear "tread" relative to the rotor radius, $t / R$. This is because, if the tread -- and, therefore, landing gear - is relatively large with respect to the rotor radius, then the landing gear takes on more of the traditional attributes of fuselage structural load bearing and hardware mounting. Takes into account fuselage structure and skins. Applies a correction factor based on the ratio of specific gravity of materials (plastic material as the base material for radiocontrolled electric helicopters); assumed to be less strength dominated weight group.

$$
m_{L G}\left(m_{G W}, t, h, \alpha\right) \approx a m_{G W}+b m_{G W}^{1 / 3}\left(t^{1+\alpha}+h^{1+\alpha}\right)^{1 /(1+\alpha)}
$$

Note that this equation has landing gear "tread" and height factors intended to accommodate large (as compared to conventional terrestrial vehicles) values of these parameters to acknowledge the importance of the rough surface terrain of Mars as well as to account for unconventional vehicle designs. Further, $\mathrm{a}=0.03$ and $\mathrm{b}=0$ for $\mathrm{t} / \mathrm{R}<0.2$, and $\mathrm{a}=0$ and $b=0.1$ when $t / R>0.2$ (assumes graphite epoxy tubing for landing gear). Note that the $\alpha$ parameter (which ranges between $0 \leq \alpha \leq 1)$ distinguishes between landing gear arrangements for such unconventional designs (such as the coaxial rotor TAMS vehicle of [6]).

All weight group results are in kilograms of mass. Note that Eq. 5 assumes that rotor blades are comprised of very thin cambered, or flat-plate circular-arc, airfoils. Further, these airfoils are assumed to be chordwise center-of-gravity balanced by using single-sheet Mylar-covered cutouts on the trailing portion of the airfoil, as shown earlier in Fig. 21.

In general, the fixed-system weight groups for the Appendix A methodology tend to be more conservative than the Appendix B methodology (Fig. 22). Correspondingly the drive system, rotor, and engine/motor categories are quite different from each other. This is chiefly a consequence of fundamentally different vehicle design approaches implicit in the two methodologies (a bit of an apple versus oranges situation). The Appendix A assumed vehicle uses electric propulsion and rotor blades with very thin cambered, circular arc, flat-plate airfoils. The Appendix B vehicle (though at an equivalent "gross weight" of $20 \mathrm{~kg}$ and payload of $2 \mathrm{~kg}$ ) is based on hydrazine reciprocating engine propulsion with a scaled advanced version of the [26] "baseline" Mars rotor with Eppler 387 blade airfoils. Therefore, the differences between the Appendix A and B estimates is a reflection of the design differences of the sized vehicles, than the estimation methodology per se. The vehicle with electric propulsion and the rotor with cambered, circular-arc, flat-plate blade airfoils, theoretically has a lower empty weight than the alternate vehicle with hydrazine propulsion and rotors with Eppler-type low Reynolds number airfoils. However, it is important to note that batteries and/or fuel cells have lower energy/power densities than hydrazine monopropellant. Overall hydrazine engine propulsion makes sense from a vehicle performance consideration, whereas electric propulsion boasts simplicity of implementation and usage that the other type of propulsion may not be able to match.
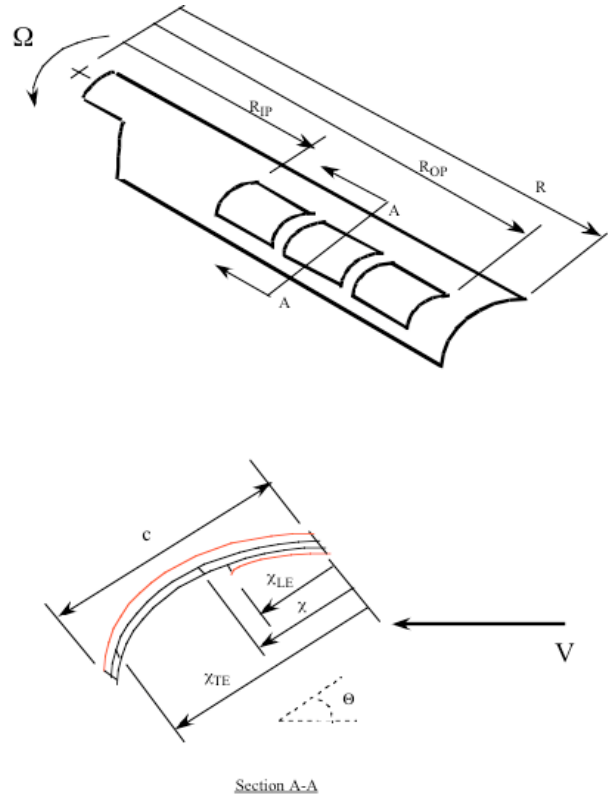

Fig. 21 - Some of the Key Cambered, Circular-arc, Flatplate Airfoil Rotor Parameters Used in defining the Weight Estimates

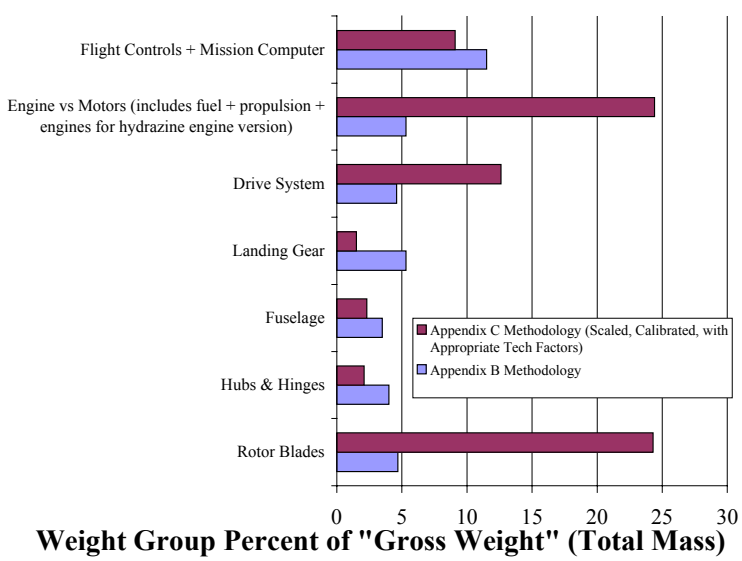

Fig. 22 - Weight Breakdown Comparison of Two Approaches to Deriving a 20Kg Mars Rotorcraft 
Table 5. Weight Estimate Tech and Calibration Factors

As an important note, the above weight trend numbers from the Appendix A methodology would suggest that a tethered hover of a $20 \mathrm{~kg}$ prototype vehicle using electric propulsion and the rotor blades with the cambered, circular-arc, flatplate airfoils (minus the power source, i.e. batteries, and payload, which would be left off the vehicle) should be feasible in a large enough vacuum/environmental chamber. Vehicle empty weight (no onboard power source, i.e., batteries) is exactly at $37 \%$ of vehicle total gross weight i.e. thrust required is nearly exactly equivalent for takeoff/hover in the chamber as would be required on Mars.

\section{APPENDIX B - WEIGHT/SIZING FOR MID TO LARGE MARS ROTORCRAFT}

The estimated weight trends for large Mars rotorcraft (greater than $150 \mathrm{~kg}$ ) are based on one or more of the three weight prediction methodologies summarized [17-18]. In some cases, particularly to address the unique aspects of the notional coaxial-tandem helicopter, the weight equations had to be modified; such changes are noted in the footnotes to Table 5. Otherwise, the weight trends for Mars rotorcraft have been accommodated by the judicious use of "Tech" and/or "Calibration" factors. The "Tech/Calibration" factors used in the Mars rotorcraft weight estimates are shown in Table 5. In most cases, these tech factors are greater than equal to unity, with the two key exceptions of the rotating rotor hardware components: the blades and hubs. In this case the hardware is assumed to be of ultra-lightweightconstruction. In he case of the rotor hubs, the prevalent use of graphite epoxy composite materials is assumed over the use of steel or titanium implicit in the [17] weight equations. For the rotor blades, a "calibration factor" was derived to match the weight characteristics of the baseline Mars rotor blades noted in [26]; further an additional 25\% knockdown factor was applied to reflect optimization of the rotor blade structural characteristics, over the baseline blades. In some cases one or more of the three [17] weight methodologies was used in the weight estimates; these methodologies were denoted with the legend T (Tischenko), BV (Boeing-Vertol), and RTL (Army Research and Technology Lab). Additionally, engine weight (rolled up into the propulsion system weigh group) was estimated by using the general methodology of [22] for reciprocating engines and applying a calibration factor for monopropellant/hydrazine-usage derived from [23]. (To fully capture the potential of large Mars rotorcraft for autonomous cargo utility and/or manned applications it will be necessary to examine in the future propulsion systems that are built around in-situ propellant generation.)

\begin{tabular}{|c|c|c|}
\hline & $\begin{array}{c}\text { Tech/Calibration } \\
\text { Factor }\end{array}$ & $\begin{array}{c}\text { Method (T, BV, } \\
\text { RTL, or R) }\end{array}$ \\
\hline Rotor Blades $^{1}$ & $\begin{array}{l}0.065 \\
0.134\end{array}$ & $\begin{array}{c}\mathrm{T} \\
\mathrm{RTL}\end{array}$ \\
\hline Hubs and Hinges $^{2}$ & 0.21 & $\mathrm{~T}$ \\
\hline Fuselage $^{3}$ & 0.27 & $\mathrm{~T}$ \\
\hline Landing Gear & 1.0 & $\mathrm{BV}$ \\
\hline Drive System & 1.0 & $\mathrm{BV}$ \\
\hline Fuel System ${ }^{4}$ & 1.25 & $\mathrm{~T}$ \\
\hline Propulsion System & 1.0 & $\mathrm{BV}$ \\
\hline Engines $^{5}$ & 0.842 & $\mathrm{R}$ \\
\hline Flight Controls $^{6}$ & 1.0 & RTL \\
\hline
\end{tabular}

${ }^{1}$ Calibration factor derived from 2.44 meter baseline Mars rotor blades [26]; additional 25\% knockdown factor. Assumes four, four-bladed rotors (with a solidity of 0.2 and tip Mach of 0.65 ).

${ }^{2}$ Tech factor defined to take into account the relative ratios of ultimate strength to specific gravity for graphite epoxy versus steel construction for hubs.

${ }^{3}$ Tech factor reflects a change of material from assumed aluminum to plastic (HDPE); based on ration of material density, not specific strength, as this is not a strength-dominated application.

${ }^{4}$ Twenty-five percent increase in tech factor to reflect increased tank complexity for safety for manned vehicles; for purely robotic vehicles would use $\mathrm{T}_{\mathrm{F}}=1.0$.

${ }^{5}$ Calibration factor derived from flight-qualified prototype Akkerman hydrazine reciprocating engine [23].

${ }^{6}$ Tech factor of unity used for RTL methodology for flight controls; however, RTL weight equation modified with a multiplier term that accounted for added control complexity for the quad-rotor coaxial-tandem helicopter configuration. This resulted in an estimate of a coaxial-tandem helicopter set of flight controls having 2.5 times higher weight than that for a single main rotor.

This approach of using tech and calibration factors in statistical weight trend equation is justifiable in the context of establishing the conceptual feasibility of larger Mars rotorcraft. As actual hardware and designs proceed from concept to maturity, the more precise estimates and weight trades can be made. Additionally, no margins are shown in Table 6; this is again primarily reflects the intent of using the above table of assessing conceptual feasibility and not defining/promoting a single point design. Further, note that this particular mix of different weight sizing methodologies is not necessarily optimal. Reference [17] discusses the relative benefits of all three methods, but concludes that no one set is superior over the other. Finally, new or updated methodologies are constantly in development within the rotorcraft community; more refined estimates will perhaps be derived from more state-of-the-art weight estimation methodologies. Finally, as detailed designs are developed then weight estimates can be based less on statistical weight equations with tailored tech/calibration factors and more on direct engineering hardware measurements.

Table 6 summarizes both the actual engineering unit and percent weights for the key helicopter weight groups for the notional $2750 \mathrm{~kg}, 6 \mathrm{~N} / \mathrm{m}^{2}$ disk load, single-passenger manned Mars rotorcraft noted earlier in the paper. Most of the 
percent weight estimates (again with the exception of the rotor hardware) are generally consistent with percent weight trends for conventional, terrestrial helicopters [18].

Table 6. Weight Breakdown for Notional Large/Manned Mars Rotorcraft

\begin{tabular}{|l|c|c|}
\hline & Mass $(\mathrm{kg})$ & \% Total Mass \\
\hline Rotor Blades $^{1}$ & 880 & 32.0 \\
\hline Hubs and Hinges & 45 & 1.6 \\
\hline Fuselage $^{2}$ & 156 & 5.7 \\
\hline Landing Gear & 42 & 1.5 \\
\hline Drive System & 241 & 8.8 \\
\hline Fuel System & 24 & 0.9 \\
\hline Propulsion System $^{3}$ & 55 & 2.0 \\
\hline Engines $^{4}$ & 250 & 9.1 \\
\hline Flight Controls $^{5}$ & 226 & 8.2 \\
\hline Payload $^{6}$ & 275 & 10.0 \\
\hline Fuel $^{7}$ & 556 & 20.2 \\
\hline & & \\
\hline Total & $2750 \mathrm{~kg}$ & $100 \%$ \\
\hline
\end{tabular}

\footnotetext{
${ }^{1}$ Assumes four, four-bladed rotors with a solidity of 0.2 , a disk loading of $6 \mathrm{~N} / \mathrm{m}^{2}$, and a tip Mach number of 0.65 .

${ }^{2}$ Assumes the majority of fuselage is comprised of open-frame truss-structure except for an abbreviated windscreen cockpit for Astronaut/pilot and elliptical section pylons (formed of thin nonstructural plastic panels) to protect the essential system components.

${ }^{3}$ Interconnect shaft is assumed to allow for overlapping and intermeshing rotors. However, OEI (one engine inoperative) capability is not assumed.

${ }^{4}$ Includes weight estimates for two Akkerman hydrazine reciprocating engines $\&$ associated auxiliary equipment.

${ }^{5}$ Boosted fixed-system flight controls assumed.

${ }^{6}$ Payload prescribed; inclusive of weight of suited Astronaut/pilot with additional life-support and EVA requirements.

${ }^{7}$ Fuel weight falls out from the overall estimation process.
}

As expected, blade weight dominates the Mars rotorcraft total weight. Therein lies the greatest payoff opportunity for an aeromechanics technology infusion into Mars rotorcraft: developing structurally and dynamically robust ultra-lightweight blade designs. Preliminary design work [16] suggests that weight fractions of approximately $12 \%$ total gross weight for overall blade weight might be feasible (at least for the $50 \mathrm{~kg}$ vehicle test case that was examined).

Referring back to Fig. 11, given the fuel estimate noted in Table 6 , the range estimates made by Breguet's formula indicate that a theoretical range of $\sim 225$ kilometers (or a radius of operation from a home base of $\sim 110$ kilometers). In actuality, a large (greater than $150 \mathrm{~kg}$ ) Mars rotorcraft would not likely use hydrazine for propellant for the vehicle engines; instead, some sort of in-situ-derived propellant/oxidizer supplies would be employed. In this case, greater range is possible. However, even in this case, reciprocating engines would still be employed (unlike terrestrial rotary-wing applications where the lighter-weight turbo-shaft engine dominates).
Finally, to conclude this weight sizing discussion, the [17] weight estimation methodology - using Table 7 tech/calibration factors - is applied to revisiting the $20 \mathrm{~kg}$, $4 \mathrm{~N} / \mathrm{m}^{2}$ disk load, robotic coaxial helicopter design problem defined in Appendix A. In this case, though, instead of cambered, circular-arc flat-plate airfoils, the rotor blades would have more conventional airfoils; further, instead of electric propulsion and RC-type servos for the control system, hydrazine Akkerman reciprocating engines are being used and more conventional mechanical-linkage fixed-system linear control actuators would be employed.

Table 7. Weight Breakdown for Hydrazine-powered 20kg Robotic Coaxial Helicopter

\begin{tabular}{|c|c|c|}
\hline & Mass (kg) & \% Total Mass \\
\hline Rotor Blades $^{1}$ & 4.86 & 24.3 \\
\hline Hubs and Hinges & 0.42 & 2.1 \\
\hline Fuselage & 0.45 & 2.3 \\
\hline Landing Gear & 0.30 & 1.5 \\
\hline Drive System & 2.51 & 12.6 \\
\hline Fuel System ${ }^{2}$ & 0.14 & 0.7 \\
\hline Propulsion System & 0.86 & 4.3 \\
\hline Engines $^{3}$ & 3.88 & 19.4 \\
\hline Flight Controls ${ }^{4}$ & 1.32 & 6.6 \\
\hline Payload $^{5}$ & 2.0 & 10.0 \\
\hline Mission Computer ${ }^{6}$ & 0.5 & 2.5 \\
\hline Fuel & 2.75 & 13.7 \\
\hline Total & $20 \mathrm{~kg}$ & $100 \%$ \\
\hline
\end{tabular}

${ }^{1}$ Assumes two, four-bladed rotors, with solidity of $0.2,4 \mathrm{~N} / \mathrm{m}^{2}$ disk loading, and a tip Mach of 0.65 .

${ }^{2}$ Fuel system tech factor reduced to unity for smaller, purely robotic, Mars rotorcraft.

${ }^{3}$ Assumes one Akkerman hydrazine reciprocating engines.

${ }^{4}$ Non-boosted, mechanical-linkage-type fixed-system flight controls assumed.

${ }^{5}$ Prescribed weight fraction which is to include any cameras or science sensors, robotic auxiliary devices (such as a robotic arms, sample grabbers, etc.), soil/rock samples returned from remote sites, and/or drop probes released at remote sites.

${ }^{6}$ Basic avionics and flight computer/autopilot functionality book-kept, along with other hardware, in the flight controls weight group. Mission computer added to weight groups to provide for higher-level mission planning and execution functionality to the aerial robot.

Figure 22, in Appendix A, incorporated the Table 7 results for the weight comparison between the two different approaches for devising a small robotic Mars rotorcraft. Other than the total pre-flight mass and payload allowable, the two vehicles and their mission profiles are quite unlike each other. This is because the higher energy density of using hydrazine as a fuel source, versus electric (battery) propulsion dictates that the two similarly sized vehicles have fundamentally different performance characteristics and, therefore, mission capabilities. 